\title{
Nonanatomic and Suture-Based Coracoclavicular Joint Stabilization Techniques Provide Adequate Stability at a Lower Cost of Implants in Biomechanical Studies When Compared With Anatomic Techniques: A Systematic Review and Meta-Analysis
}

\author{
Theodorakys Marín Fermín, M.D., Jean Michel Hovsepian, M.D., \\ Víctor Miguel Rodrigues Fernandes, M.D., Ioannis Terzidis, M.D., B.Sc., Ph.D., F.E.B.S.M., \\ Emmanouil Papakostas, M.D., F.E.B.S.M., and Jason Koh, M.D., M.B.A., F.A.A.O.S.
}

\begin{abstract}
Purpose: To compare the stability and cost of the used implants in nonanatomic and anatomic acromioclavicular joint repair/reconstruction (ACCR) techniques tested in cadaveric shoulder biomechanical studies during the last decade. Methods: A systematic review and meta-analysis were performed following the Preferred Reporting Items for Systematic Reviews and Meta-Analyses guidelines and prospectively registered in PROSPERO. Two independent reviewers searched PubMed, Embase, and Virtual Health Library databases. Studies evaluating 3-direction stability under 70-N loads and loadto-failure protocols with servohydraulic testing systems were included. A meta-analysis of the mean differences of anterior, posterior, and superior direction; relative stability value in 3 directions; superior direction load-to-failure; stability/cost index; and load-to-failure/cost index was performed using a continuous random-effects model and $95 \%$ confidence interval. Results: Eighteen articles were included. Both non-ACCR and ACCR techniques exceeded the minimum acceptable threshold of stability and load-to-failure. ACCR techniques were biomechanically better in terms of anterior stability $(P=.04)$ and relative stability value (mean difference $64.08 \%, P=.015)$. However, supraphysiological stability and failure loads were achieved with non-ACCR techniques at a lower cost of implants. Techniques combining 2 clavicular tunnels separated by at least $10 \mathrm{~mm}$, a mean of 2 sutures, and/or suture tapes had the greatest stability/cost index and load-to-failure/cost index among the included techniques (confidence interval 99\%). Conclusions: NonACCR and ACCR techniques exceeded the minimum acceptable threshold of stability and failure loads in controlled biomechanical testing. However, non-ACCR and techniques combining 2 clavicular tunnels separated by at least $10 \mathrm{~mm}$, a mean of 2 sutures, and/or suture tapes provide supraphysiologic stability and failure loads at a lower cost of implants. Clinical Relevance: Non-ACCR and suture-based techniques may provide more cost-effective and greater value treatment for acromioclavicular joint injury and could be considered in the surgical management of normal activity individuals and cost-sensitive populations.
\end{abstract}

\footnotetext{
From the Department of Traumatology. Hospital Periférico de Coche "Dr. Leopoldo Manrique Terrero," Caracas, Venezuela (T.M.F.); Department of Orthopaedic Sports Medicine, Chirurgisches Klinikum München Süd, Munich, Germany (J.M.H.); Department of Traumatology, Clinica Santa María de la Asunción, Tolosa, Spain (V.M.R.F.); TheMIS Orthopaedic Center, Thessaloniki, Greece (T.M.F., I.T., E.P.); Aspetar Orthopedic and Sports Medicine Hospital, Doha, Qatar (E.P.); and NorthShore University Health System, Evanston; University of Chicago Pritzker School of Medicine, Chicago; and Northwestern University School of Engineering. Evanston, Illinois, U.S.A. (J.K.).

The authors report that they have no conflicts of interest in the authorship and publication of this article. Full ICMJE author disclosure forms are available for this article online, as supplementary material.
}

This paper is presented as the result of the 2019-2021 International Society of Arthroscopy, Knee Surgery and Orthopaedic Sports Medicine (ISAKOS) Scientific Committee Research Mentoring Program.

Received July 8, 2020; accepted December 29, 2020.

Address correspondence to Theodorakys Marín Fermin, M.D., Hospital Periférico de Coche "Dr. Leopoldo Manrique Terrero," Av. Intercomunal con calle Zea, Coche,PO: 1090, Caracas, Venezuela.E-mail: theodorakysmarin@ yahoo.com

(C) 2021 THE AUTHORS. Published by Elsevier Inc. on behalf of the Arthroscopy Association of North America. This is an open access article under the CC BY-NC-ND license (http://creativecommons.org/licenses/by-nc-nd/4.0/). 2666-061X/201101

https://doi.org/10.1016/j.asmr.2020.12.007 
A cromioclavicular (AC) joint injuries are one of the most common in the young athlete's shoulder. ${ }^{1-4}$ The typical injury mechanism is a direct trauma from falling onto the shoulder's superior aspect with the arm in adduction and the subsequent medial and inferior translation of the acromion, which jeopardizes the joint ligament's complex and stability. ${ }^{5,6}$

AC joint ligament's complex comprises intrinsic structures such as the AC capsule; anterior, posterior, superior, and inferior ligaments; and the extrinsic coracoclavicular (CC) ligaments, named the conoid and trapezoid ligament. ${ }^{5}$ The conoid ligament arises from the coracoid process base and inserts in the conoid tubercle, spanning 3 to $5 \mathrm{~cm}$ medial from the clavicle's lateral edge. Conversely, the trapezoid ligament arises from the coracoid process's superior aspect and inserts in the trapezoid ridge at 1.5 to $3 \mathrm{~cm}$ medial from the clavicle's lateral edge. ${ }^{7}$

From a biomechanical standpoint, the intrinsic ligaments assist in posterior clavicle translation and posterior axial rotational stability. ${ }^{5,8,9}$ Likewise, the conoid ligament resists anterior and superior clavicle translation, and the trapezoid ligament contributes to the horizontal and vertical stability, especially during acromial compression. $5,8,9$

Several factors, such as the severity of the injury, chronicity, sports activities, and rehabilitation compliance, are considered when deciding the treatment option. ${ }^{5,10}$ Conservative treatment is the most common approach and has been recommended for Rockwood I and II AC joint injuries, whereas the surgical approach has been advocated for Rockwood type IV and VI.,11 However, it is still controversial for type III and V injuries. ${ }^{5,10,12-14}$

New studies have challenged the current algorithms, as conservative treatment has shown faster recovery and similar pain outcomes than surgical treatment, ${ }^{15}$ even in high-grade injuries. ${ }^{14,16}$ In addition, surgical treatment is reportedly associated with prolonged hospitalizations and recovery but with greater reoperation rates due to implant-related complications. ${ }^{16}$

Also, interrogations about standard treatment still arise when considering that at least one half of the world's population does not have access to quality essential services to protect and promote health. ${ }^{17}$ It seems from an economic standpoint that conservative management is the most cost-effective treatment; however, no study has been conducted on this topic.

Despite the results favoring nonoperative treatment, some populations may benefit from surgical intervention, especially those with high functional demands and athletes. ${ }^{16,18}$ A plethora of techniques have been described for this sole joint stabilization. ${ }^{4,15,19}$ Nevertheless, the orthopaedic community has not found a standard technique. ${ }^{4,5}$ With the introduction of anatomic principles in the repair/reconstruction of CC ligaments ${ }^{20}$ and the findings of AC capsule and intrinsic ligament's role, multiple studies about anatomic acromioclavicular joint repair/reconstruction (ACCR) techniques were conducted in the last decade. ${ }^{21,22}$ Accordingly, several implants were developed to meet those purposes. ${ }^{5,6,23}$

Although the ligaments' biomechanical specificity motivated the reproduction of the native anatomy during these novel repair/reconstruction techniques, their clinical advantage has not met the expectations. ${ }^{24,25}$ Recent evidence reveals similar clinical outcomes, complications, failure, and return to sports rates between techniques, ${ }^{4,18,21,26}$ which may imply that it is not clinically relevant to recreate both ligaments.

Thus far, some authors have expressed their concern about the cost of the implants, ${ }^{27-32}$ surgical technique, ${ }^{23}$ surgical approach, ${ }^{33-35}$ total surgery costs, ${ }^{34}$ and postoperative recovery. ${ }^{36}$ However, only a few studies have evaluated the cost of the AC joint repair/reconstruction surgery, and those comparing the cost-effectiveness between techniques reveal significant differences in consumables and materials among them. ${ }^{27,33,37}$ Abdelrahman et al., ${ }^{37}$ in a randomized controlled study, reported significant differences in the cost of consumables (arthroscopic \$1729.95 vs open \$851.7) but no differences in terms of the operation room and hospital charges. Similarly, significantly greater material costs were found when comparing the cortical button system and Kirschner wire fixation $(€ 340 \pm 123.7 \text { vs. } € 4)^{27}$ and cortical button system versus Kirschner wire combined with suture tape ( $€ 400$ vs $€ 82.5-85$ ), without significant differences in other items. ${ }^{33}$

The purpose of this study was to compare the stability and cost of the used implants in non-ACCR and ACCR techniques tested in cadaveric shoulder biomechanical studies during the last decade. We hypothesized that non-ACCR techniques would provide adequate stability at a lower cost of implants.

\section{Methods}

This systematic review and meta-analysis were conducted following the Preferred Reporting Items for Systematic Reviews and Meta-Analyses (PRISMA) guidelines and were prospectively registered in PROSPERO.

\section{Search Strategy}

Two independent reviewers (T.M., V.R.) searched PubMed, EMBASE, and Virtual Health Library databases up to March 25, 2020. The following terms, "acromioclavicular," "acromioclavicular joint," "AC joint," "coracoclavicular," "coraco clavicular," "repair," "reconstruction," "biomechanical testing," "biomechanical test," "biomechanical comparison," "biomechanical analysis," "biomechanical study," and "biomechanics," were used alone and in combination with Boolean operators AND caraco OR. Filters were applied to screen only investigations in the last 10 years. Inclusion and exclusion criteria were established before the search and were used 
to identify the potentially eligible studies by title and abstracts screening. Disagreements between reviewers were carried through the next round of screening for full-text assessment in potential eligible studies for inclusion. If any, the senior author (J.K.) resolved disagreements in article inclusion.

\section{Eligibility Criteria}

Controlled laboratory studies evaluating AC joint stability with different repair/reconstruction techniques in shoulder cadaveric specimens with servohydraulic testing systems were screened for inclusion. Studies were considered eligible for this systematic review if they fulfilled all the following predefined criteria: (1) controlled laboratory studies written in English and Spanish; (2) a minimum of 6 shoulder specimens per group; (3) reporting anterior, posterior, and superior translation in millimeters with loads of $70 \mathrm{~N}$ in native joints and after the proposed repair/reconstruction technique; and/or reporting superior direction failure load in Newtons; (4) disclosing with detail the implants used in the repair/reconstruction technique; and (5) published in the last 10 years.

Three-direction biomechanical protocols under $70-\mathrm{N}$ loading were preferred because they are representative of shoulder forces during postoperative physical therapy. ${ }^{38}$ Excluded studies met at least 1 of the following criteria: (1) evaluated biomechanical properties of the AC joint without comparing CC repair/ reconstruction with/without AC repair/reconstruction technique, (2) tested risk of clavicle or coracoid process fracture, or (3) were conducted in artificial models.

\section{Data Extraction}

Two reviewers independently reviewed the included studies, and data were extracted and presented in a table. All disagreements were resolved by consensus by a discussion with a third individual. Data extraction was based on a predefined Excel spreadsheet (Microsoft, Redmond, WA) with the following variables: (1) first author, (2) year of publication, (3) number of specimens, (4) surgical technique, (5) biomechanical protocol, (5) post-loading translational testing results of native and described technique, (6) load-to-failure results, and (7) implants involved in the technique.

\section{Methodologic Quality Assessment}

The quantitative content assessment was performed using the STROBE Statement checklist (SSc), identifying individual studies bias risk. The Pearson test was employed to evaluate the possible association with the year of publication of the studies and highlight any possible improvement of the methodology through the years.

\section{Statistical Analysis}

Cohen's kappa ( $\kappa)$ was calculated for title and abstract screening interrater reliability. We designed 2 indexes to assess the correlation between stability and implants' cost for this study: the stability/cost index (SCI) and the loadto-failure/cost index (LtFCI). SCI value can be interpreted as the percentage of 3-direction stability per dollar, or when multiplied per 100, the percentage of 3-direction stability per every $\$ 100$. Correspondingly, LtFCI relates to the number of Newtons to failure per dollar.

To calculate the proposed SCI, the relative stability of the technique was divided by the cost of the implants used in the technique. Likewise, the for suggested LtFCI, the superior direction load-to-failure was divided by the cost of the implants used in the technique.

Relative stability value (RSV) was computed for every surgical technique tested in 3-direction protocols under $70 \mathrm{~N}$. RSV was considered as the resulting stability after a repair/reconstruction technique (dividend) compared with the native joint stability (divisor) in the form of a percentage (per 100). Being (1) the dividend, the stability of the repaired/reconstructed joint was calculated based on the sum of mean post-loading translations $(\mathrm{mm})$ after 70- $\mathrm{N}$ loading in anterior, posterior, and superior direction; and (2) the divisor, the sum of the superior standard deviation (SD) of native post-loading translation (millimeter) of the joint after 70-N loading in anterior, posterior, and superior direction in the native specimen.

According to the reference prices obtained from 4 manufacturers' sales representatives from America and Europe, the implants' costs were estimated. According to their type, average prices were given to implants regardless of the specific manufacturer (Table 1). Allografts were not considered for cost estimation since autologous tissue could be substituted.

Three independent investigators carried out the SCI and LtFCI calculation. Results were averaged, and indexes were assigned for every technique accordingly. Techniques were grouped following a modification of the Beitzel et al. ${ }^{39}$ categorization in (1) non-ACCR, in which the CC ligaments repair/reconstruction was performed without considering their native anatomic positioning (including hook plate osteosynthesis) and/ or involving CA ligament transfer; (2) ACCR, in which the CC ligaments repair/reconstruction was performed restoring their anatomic position; and (3) ACCR + AC cerclage (ACCR + AC), in which the anatomically restored CC ligaments were accompanied with AC ligament cerclage (Table 2).

Correlations between year and (1) stability under $70-\mathrm{N}$ loads in 3 directions, (2) superior direction loadto-failure, and (3) cost of implants were calculated using Pearson's coefficient, looking for statistical significance. Statistical significance was calculated using $P<.1, .05, .01$, and .001 .

A meta-analysis of mean difference (MD) of (1) anterior, posterior, and superior direction under $70-\mathrm{N}$ loads; (2) stability relative value in 3 directions under 70-N loads; (3) superior direction load-to-failure; 
Table 1. Mean Cost of Implants for Acromioclavicular Joint Repair/Reconstruction

\begin{tabular}{lc}
\hline \multicolumn{1}{c}{ Implants } & Cost, \$ \\
\hline Locking hook plate & 750 \\
Synthetic ligament system & 800 \\
Sutures & 40 \\
Suture tapes, fiber mesh, braided cords & 85 \\
Cortical buttons & 85 \\
Two-cortical button systems & 350 \\
Three-cortical button systems & 850 \\
Interference screws & 215 \\
Suture anchors & 285 \\
\hline
\end{tabular}

(4) SCI; and (5) LtFCI was performed using a continuous random-effects model and 95\% CI. Heterogeneity was calculated with the $\mathrm{I}^{2}$ test. Forest plot graphics were generated for each condition. Adjustments using Bonferroni method (alpha $=0.05$ ) were made for multiple comparisons. Statistical analysis was performed using OpenMetaAnalyst ${ }^{40}$ and Microsoft Excel 2016 (Microsoft, Redmond, WA).

\section{Results}

\section{Search Results}

The initial literature search yielded 376 potentially relevant records after the removal of duplicates. After we screened titles and abstracts, 56 articles were retrieved for full-text evaluation $(\kappa=0.91)$. Twenty-one biomechanical controlled laboratory studies met the predetermined eligibility criteria, and 18 were eventually included with a total agreement in the systematic review, as shown in the PRISMA flow diagram (Fig 1).

A total of 41 AC joint repair/reconstruction techniques were examined. From the 18 included studies, 6 consisted of 70- $\mathrm{N}$ testing protocols in anterior, superior, and posterior direction ${ }^{28,41-45}$ and 16 superior direction load-to-failure protocols. ${ }^{23,30,31,41,42,44-54}$

\section{Synthesis of Results}

\section{Stability Meta-Analysis}

Stability meta-analysis of 5 studies showed that both non-ACCR and ACCR techniques met or exceeded physiologic stability. ACCR showed statistically significant superiority of anterior stability than non-ACCR techniques (weighted mean: $5.16 \mathrm{~mm} \pm 1.85$ vs 10.45 $\mathrm{mm} \pm 2.11, P=.04$ ) (Fig 2A). The pooled weighted mean of the available native anterior translation under 70-N loads of 68 specimens among 5 studies ${ }^{41-45}$ was $6.90 \pm 2.42 \mathrm{~mm}$. Posterior and superior translations under $70 \mathrm{~N}$ were not statistically different between groups (Fig 2 B and C). Similarly, when we compared RSV, ACCR techniques had greater stability, showing a mean of $64.08 \%$ more stability (weighted mean: 194.26 $\pm 23.51 \%$ vs $137.81 \pm 25.49 \%, P=.015)($ Fig $2 \mathrm{D})$.

\section{Load-to-Failure Meta-Analysis}

Seven studies were available for superior direction load-to-failure comparison. Superiority was found in

Table 2. Categorization of AC Joint Repair/Reconstruction Techniques

\begin{tabular}{|c|c|c|}
\hline Non-ACCR & ACCR & ACCR + AC Cerclage \\
\hline 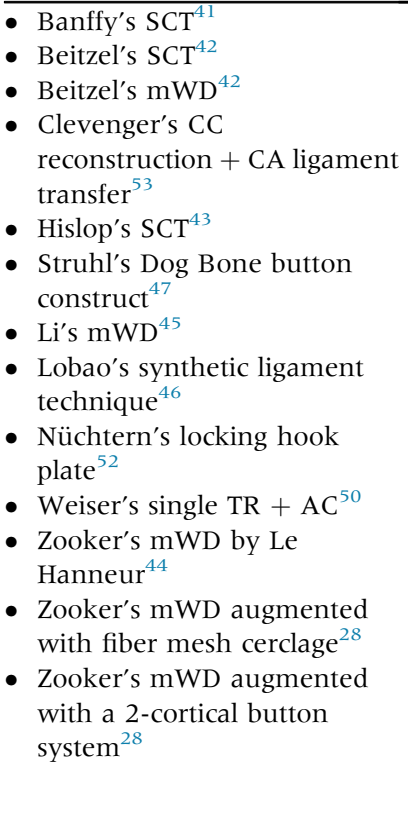 & 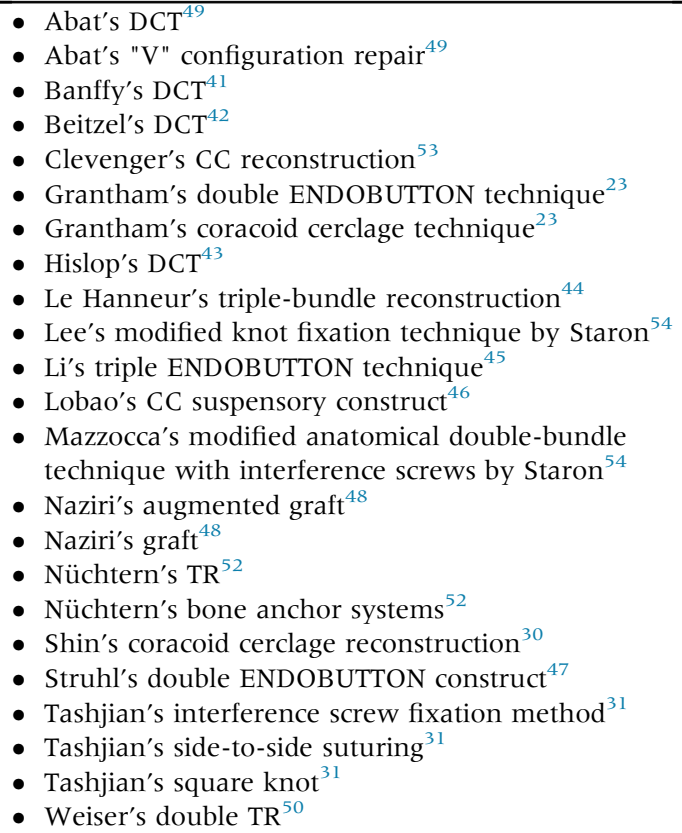 & $\begin{array}{l}\text { - Hislop's DCT + AC suture } \\
\text { - Martetschläger's PDS cerclage reconstruction } \\
\text { - Shin's single-tendon anatomic AC-CC } \\
\text { reconstruction } \\
\text { - Weiser's double TR }+\mathrm{AC}^{50} \\
\text { - Weiser's PDS sling }+\mathrm{AC}^{50}\end{array}$ \\
\hline
\end{tabular}

AC, acromioclavicular; ACCR, anatomic acromioclavicular joint repair/reconstruction; CA, coraco-acromial; CC, coracoclavicular; DCT, double clavicular tunnel; mWD, modified Weaver-Dunn; PDS, polidioxanone; SCT, single clavicular tunnel; TR, TightRope. 


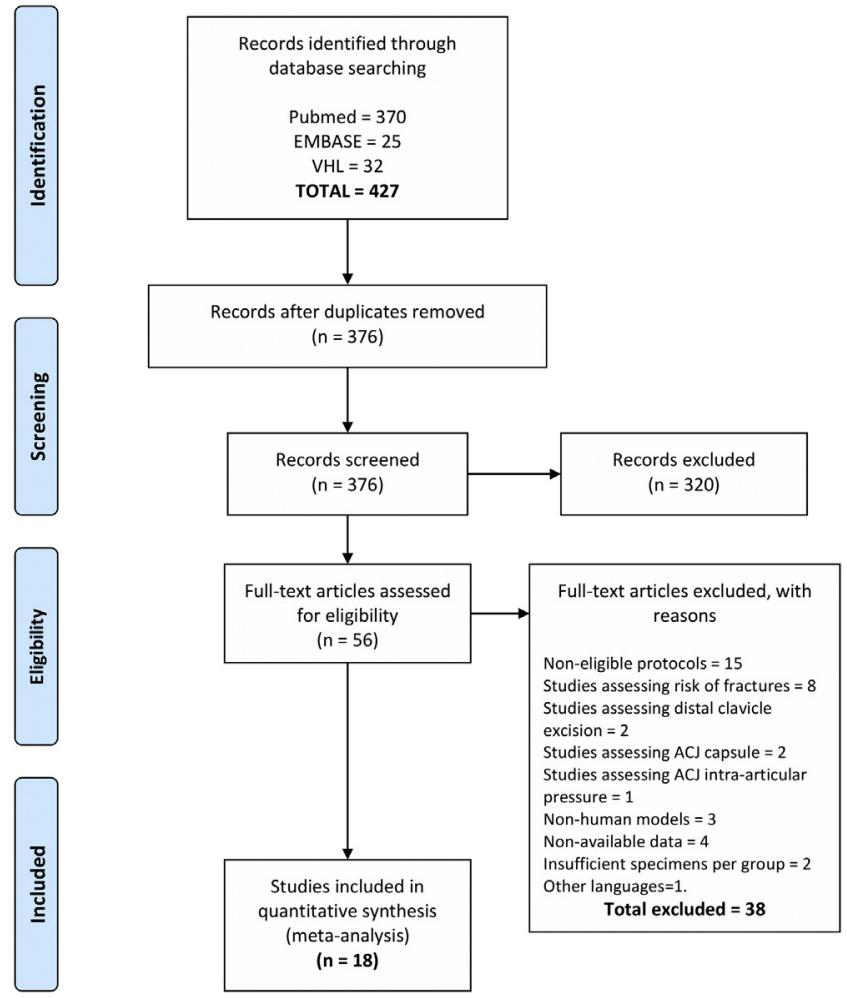

Fig 1. Search strategy and study selection process using the Preferred Reporting Items for Systematic Reviews and MetaAnalyses methodology.

the ACCR group, showing a mean of $185.83 \mathrm{~N}$ more than the non-ACCR group (weighted mean: $591.72 \pm$ $154.12 \mathrm{~N}$ vs $425.31 \pm 138.42 \mathrm{~N}, P=.07$ ) (Fig 3A). The pooled weighted mean of the available native failure loads of 65 specimens among 5 studies $^{42,45,49,51,54}$ was $538.13 \pm 114.48 \mathrm{~N}$. The lower SD (423.66 N) was considered as the minimum physiologic failure load. Only 2 studies were available for comparison between ACCR and ACCR + AC techniques for superior direction load-to-failure, favoring ACCR + AC techniques without statistical significance (Fig 3B).

\section{Stability and Cost Behavior Over the Last Decade}

A total of 41 techniques were evaluated for SCI and/ or LtFCI. Among 14 techniques (6 studies) assessing stability in anterior, posterior, and superior direction under $70-\mathrm{N}$ loads, the Pearson coefficient revealed an improvement of the RSV of the AC joint over the last decade $(P=.026)$, with a negative correlation for superior direction load-to-failure improvement in 36 techniques (16 studies), although not statistically significant. In contrast, there was an increase in the implants' cost in 41 techniques (18 studies) over the last decade $(P=.08)$.

\section{SCI Meta-Analysis}

SCI meta-analysis was conducted in 5 studies $^{41-45}$ comparing non-ACCR versus ACCR techniques
(Fig 4A). Non-ACCR techniques had favorable results, with $10.2 \%$ more stability per every $\$ 100$ (weighted mean: SCI $0.465 \pm 0.121$ vs $0.328 \pm 0.037$, cost of implants $\$ 348.29$ vs $\$ 666.5$ ).

Overall mean SCI was $0.424 \pm 0.251$ (range 0.148 1.137) of 14 eligible techniques. Techniques denoted with an asterisk $\left({ }^{*}\right)$ exceeded the minimum acceptable threshold of stability (Table 3 ). The greatest indexes (CI 99\%) were found in Beitzel et al.'s modified WeaverDunn, Hislop et al.'s single clavicular tunnel, and Hislop et al.'s double clavicular tunnel (SCI 1.137, 0.671 , and 0.657 , respectively). ${ }^{43,44}$

\section{LtFCI Meta-Analysis}

LtFCI meta-analysis of 7 studies $^{41-46,52}$ revealed favorable results for ACCR techniques, with $21.2 \mathrm{~N}$ more to failure per every $\$ 100$ (weighted mean: SCI 1.361 vs 1.304 , cost of implants $\$ 444.71$ vs $\$ 612.30$ ) (Fig 4B). Overall mean LtFCI was $2.473 \mathrm{SD} \pm 3.287$ (range 0.220-15.370) of 36 eligible techniques. Techniques denoted with an asterisk $(*)$ exceeded the minimum acceptable threshold of load-to-failure (Table 4). The techniques with the greatest indexes (CI 99\%) were Tashjian et al.'s ACCR with graft square knot, Tashjian et al.'s ACCR with graft side-to-side suturing, Clevenger et al.'s ACCR reconstruction, Clevenger et al. 's ACCR reconstruction + coracoacromial (CA) ligament transfer, Weiser et al. 's ACCR polidioxanone + AC cerclage, Lobao et al.'s ACCR suspensory construct, and Beitzel et al.'s modified Weaver-Dunn (LtFCI 15.370, 12.768, 8.086, 5.954, $4.512,4.413$, and 3.889 , respectively)..$^{1,42,46,50,53}$

\section{Common Aspects Among Greatest $\mathrm{SCl}$ and $\mathrm{LtFCl}$ Surgical Techniques}

From the 9 surgical techniques with the greatest SCI and LtFCI, all of them used a mean of 2 sutures and/or suture tapes, ${ }^{31,42,43,46,51,52} 8$ included 2 clavicular tunnels separated by at least $10 \mathrm{~mm},{ }^{31,42,43,46,50,53} 5$ had distal clavicle excisions, ${ }^{31,41,42} 4$ implemented grafts, ${ }^{31,53}$ and 2 CA ligament transfer. ${ }^{42,54}$ Beitzel et al.' $\mathrm{s}^{42}$ modified Weaver-Dunn technique was the only technique showing high SCI and LtFCI, but with suboptimal RSV $(90.95 \%)$ and failure load $(311.13 \mathrm{~N})$.

\section{Methodologic Evaluation}

The SSc was used to assess the quality of the report of the studies included in the present systematic review and meta-analysis (Table 5). The average SSc value was 29.11 of 32 (range 28-31), demonstrating a high methodologic quality level. However, of the items that compose the SSc: (1) 10 studies failed to report "how the sample size was arrived at" and the "description of analytical methods that took account of sampling strategy"23,28,41,42,45,48-52 (2) 4 studies failed to report the mean age of the cadaveric specimens, ${ }^{31,43,52,53}$ 


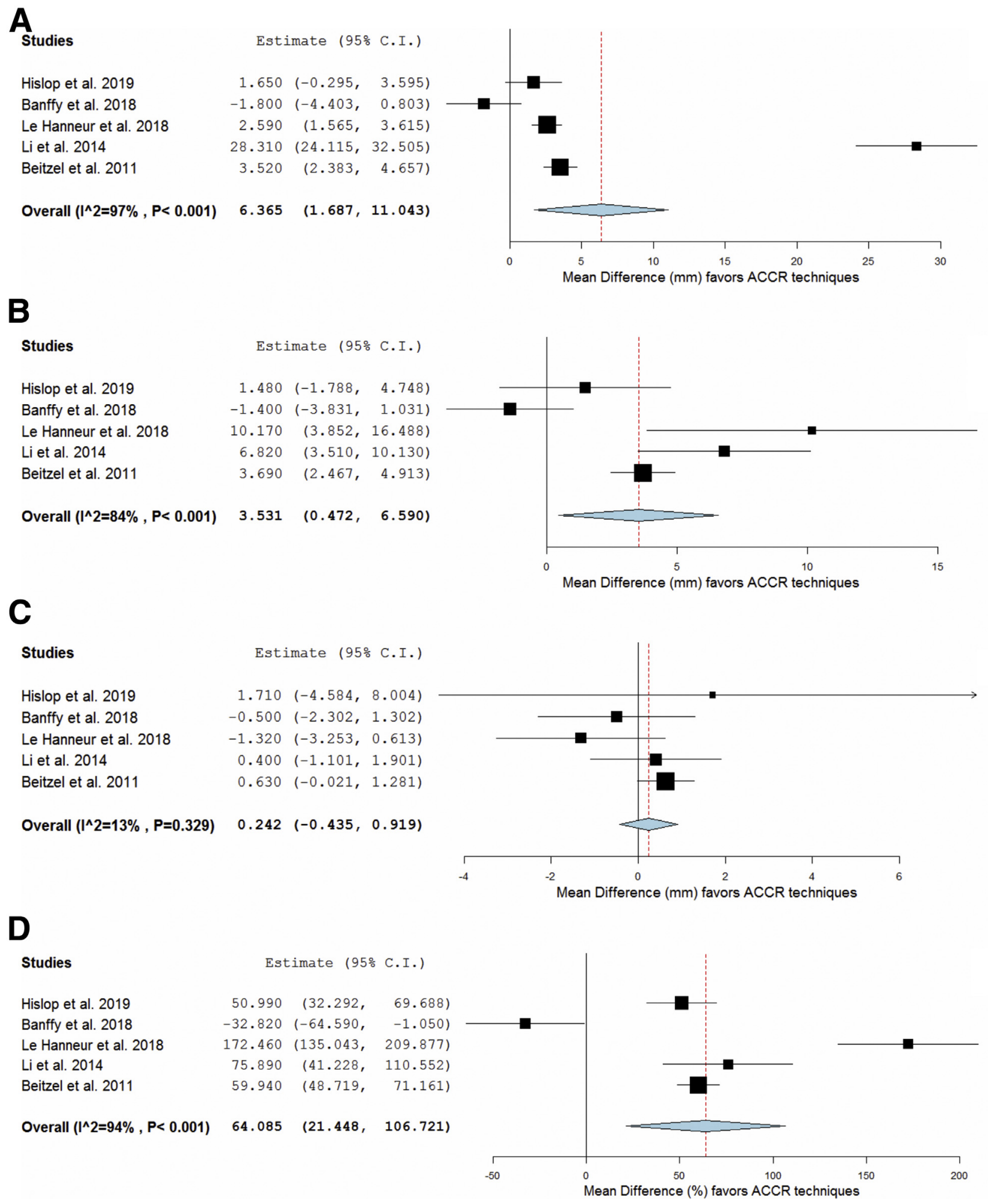

Fig 2. Meta-analysis on translation in 70-N biomechanical protocols comparing acromioclavicular joint anatomic vs. nonanatomic repair/reconstruction techniques during the last decade: (A) anterior translation ( $\mathrm{mm})$, (B) posterior translation $(\mathrm{mm}),(\mathrm{C})$ superior translation $(\mathrm{mm})$, and (D) relative stability value (\%). (ACCR, anatomic acromioclavicular joint repair/ reconstruction; CI, confidence interval.)

(3) 3 studies did not clearly define failure, ${ }^{30,42,45}$ and (4) one did not report the $\mathrm{mm} / \mathrm{min}$ rate for load-tofailure testing. ${ }^{41}$ It is also important to point out that only 3 studies performed bone mineral density and/or computed tomography analysis on the specimens. ${ }^{50,52,54}$ 


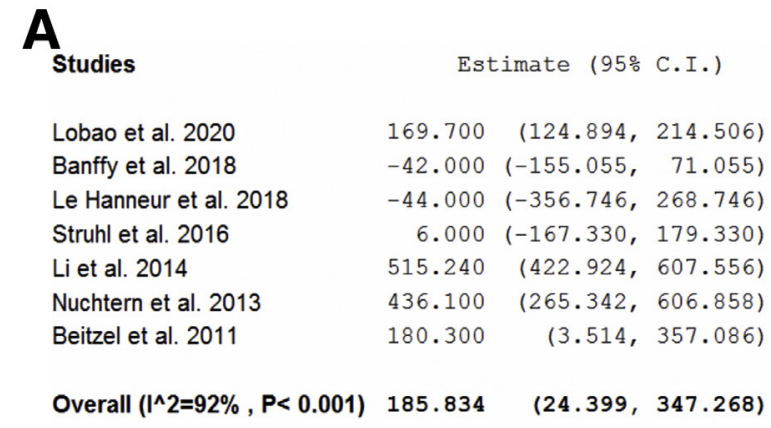

B

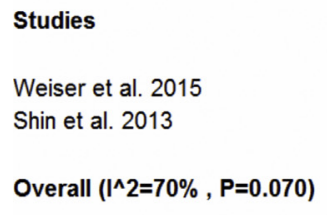

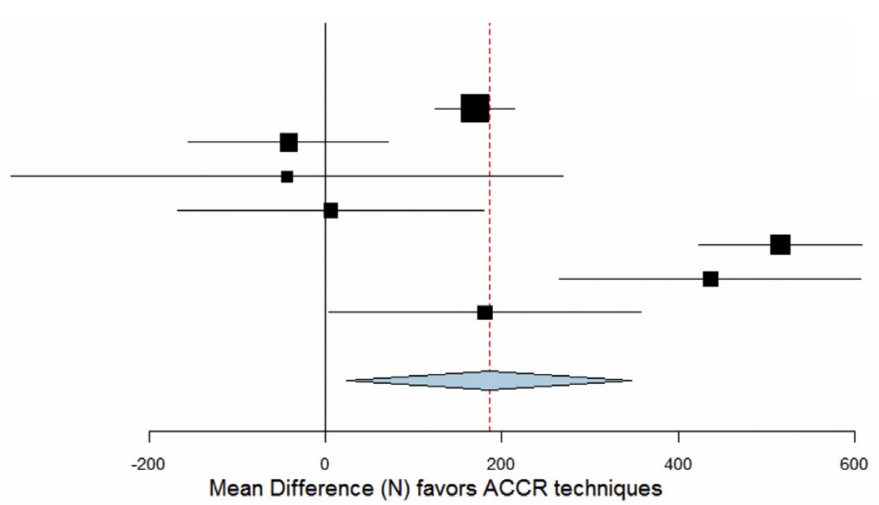

Mean Difference $(\mathrm{N})$ favors $\mathrm{ACCR}$ techniques

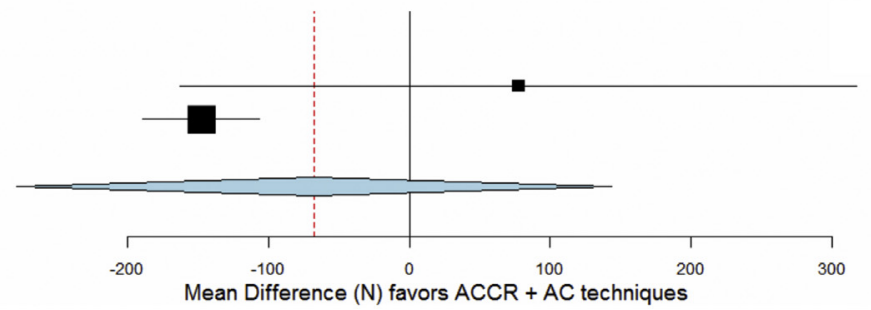

Fig 3. Meta-analysis on superior direction load-to-failure $(\mathrm{N})$ biomechanical protocols comparing acromioclavicular joint repair/reconstruction techniques during the last decade: (A) anatomic versus nonanatomic techniques, (B) anatomic versus anatomic + AC cerclage techniques. (AC, acromioclavicular; ACCR, anatomic acromioclavicular joint repair/reconstruction; CI, confidence interval.)

Association analysis of the SSc score and year of publication with Pearson's coefficient showed a significant positive association $(P=.047)$.

\section{Assessment of Publication Bias}

Evaluation of the included studies' publication bias was performed using the ROBIS tool ${ }^{55}$ (Fig 5). The risk of bias in the review was found to be low. Nevertheless, concerns regarding the standardization of implants' cost and heterogeneity of surgical techniques and measurement methods should be noted. Heterogeneity tests were conducted and interpreted as follows: $\mathrm{I}^{2} \leq 25 \%$, low heterogeneity; from $26 \%$ to $74 \%$, moderate heterogeneity; and $\geq 75 \%$, high heterogeneity. A high heterogeneity level was identified, ranging in most comparison groups between $70 \%$ and $99 \%$.

\section{Discussion}

The most important finding of this study is that ACCR techniques were biomechanically better than the nonACCR in terms of anterior stability $(P=.04)$, RSV (MD 64.08\%, $P=.015$ ), and failure loads (MD 185.83 $\mathrm{N}, P=.07)$. However, supraphysiological stability and failure loads can be achieved with non-ACCR techniques at a lower cost of implants, as originally hypothesized.

ACCR techniques have failed to demonstrate clinical superiority over non-ACCR techniques, as reported by several authors. ${ }^{4,18,21,26}$ A systematic review of 34 studies by Moatshe et al. ${ }^{21}$ showed comparable patientreported outcomes measures (PROM) regardless of the surgical technique. Reconstruction techniques involving free graft scored the highest PROM and fewest complications than those involving a hook plate or K-wires. Also, Gowd et al. ${ }^{4}$ conducted a systematic review composed of 58 articles collecting the complication profiles of open and arthroscopic surgical techniques. No differences were found in the complication rate, revision rate, and loss of reduction among them. Similarly, in a systematic review including 28 studies, Xará-Leite et al. ${ }^{26}$ reported comparable postoperative outcomes, pooled failure, and reoperation rates between non-ACCR and ACCR techniques in managing chronic AC joint injuries.

It was theorized that the improvement of PROM in the surgical treatment of AC joint dislocations with non-ACCR and ACCR techniques is attributable to the supraphysiological RSV that can be achieved with both techniques in the biomechanical laboratory setting (weighted mean: $194.26 \% \pm 23.51$ vs $137.81 \% \pm$ $25.49, P=.015)$. Even when ACCR techniques provide significantly greater stability (MD 64.08\%, $P=.015$ ) and greater failure loads (MD $185.83 \mathrm{~N}, P=.07$ ), they do not seem to translate into significantly better outcomes or fewer complication rates according to previously reported systematic reviews. $4,5,10,14,21,22$ 


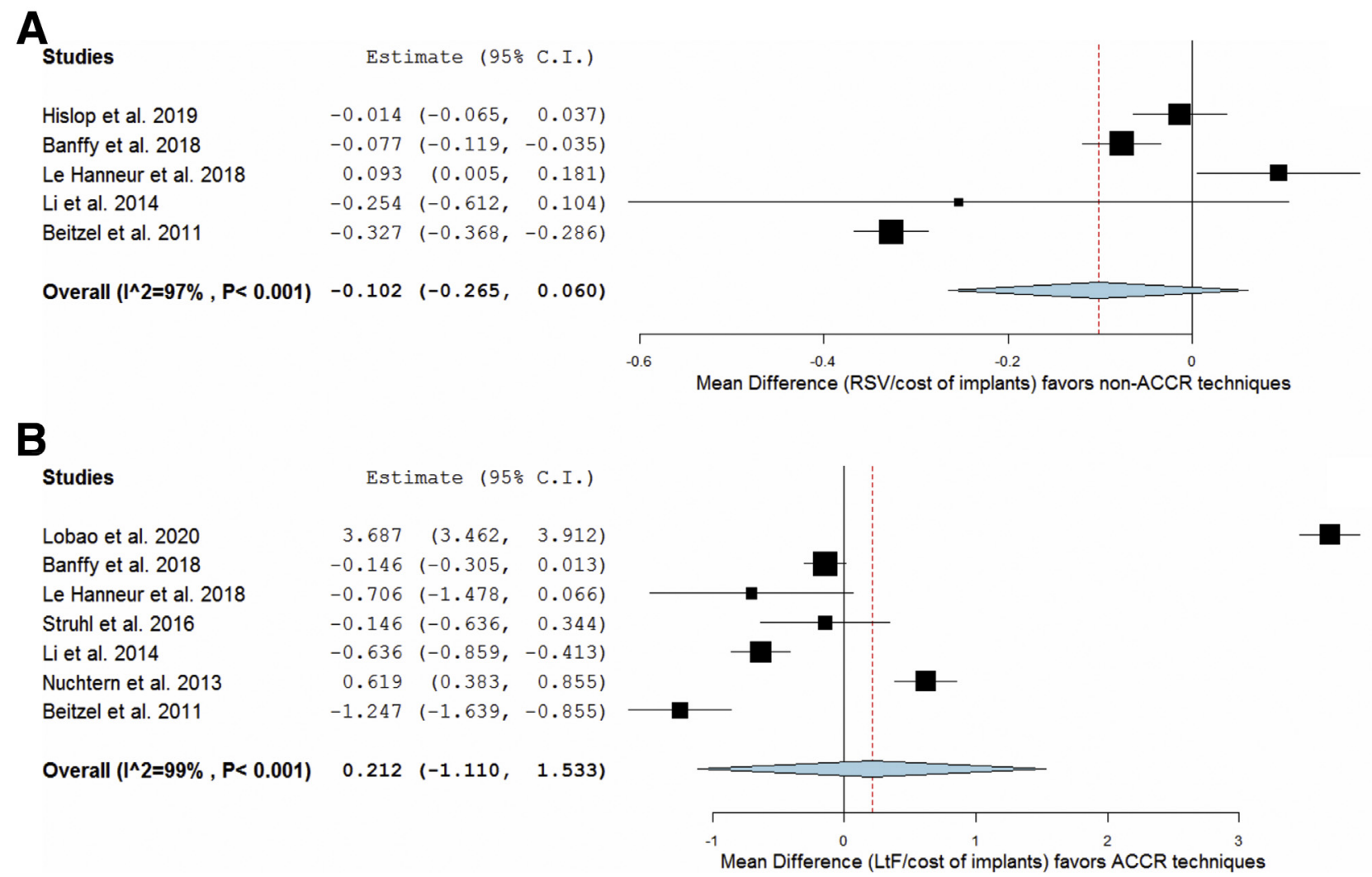

Fig 4. Meta-analysis comparing acromioclavicular joint anatomic versus nonanatomic repair/reconstruction techniques in biomechanical experiments during the last decade on: (A) stability/cost index, (B) load-to-failure/cost index. (ACCR, anatomic acromioclavicular joint repair/reconstruction; CI, confidence interval; RSV, relative stability value.)

All societies are interested in high-quality health care at a lower cost and are particularly crucial in costsensitive situations. According to the Tokyo Declaration on Universal Health Coverage, at least one half of the world's population still does not have access to quality essential services to protect and promote health, and 800 million people are spending at least $10 \%$ of their household budget on out-of-pocket health care expenses. Nearly 100 million people are being pushed into extreme poverty each year due to health care costs. ${ }^{17}$ Although access to surgical care and costeffectiveness of AC joint dislocations treatment is out of the scope of this systematic review and metaanalysis, our evaluation of 3-direction stability and the cost of implants suggests better indexes for the nonACCR techniques. Moreover, the presented experimental evidence suggests the lack of clinical benefit from extra stability despite the trend toward the increment in 3-direction stability $(P=.026)$ and the cost of used implants in the last decade $(P=.08)$.

Our findings also endorse the techniques combining 2 clavicular tunnels separated by at least $10 \mathrm{~mm}$, a mean of 2 sutures, and/or suture tapes as those to have the greatest SCI and LtFCI among all the included techniques (CI 99\%). The equivalent loss of reduction between suture-only fixation versus cortical button systems compared with all other reconstruction techniques reported by Gowd et al. ${ }^{4}$ supports our results in favor of suture-based fixation, considering its lower costs.

Beitzel et al.'s modified Weaver-Dunn was the only technique having high SCI and LtFCI, but with suboptimal RSV $(90.95 \%)$ and failure load $(311.13 \mathrm{~N})$. Furthermore, it joined with four other techniques comprising distal clavicle excision ${ }^{31,42,53}$ among the 9 displaying the greatest indexes. Distal clavicle excision techniques have been related to significantly greater horizontal instability ${ }^{56-59}$ and modified Weaver-Dunn, with fewer load-to-failure than native specimens. ${ }^{28,42,45}$ However, another biomechanical study of the modified Weaver-Dunn procedures shows contrasting results. ${ }^{44}$ Moreover, new clinical evidence reveals equivalent clinical outcome, complication, and failure rates between the modified Weaver-Dunn procedure and other ACCR techniques. ${ }^{4,21,22}$ Thus, modifications of this technique and distal clavicle excision may still be relevant in our time.

This study does not contemplate conservative treatment. Chang et al. evaluated the functional outcome of conservative and surgical treatment of high-grade AC joint dislocations (including grade III injuries), finding no differences. A faster return to work was observed in 
Table 3. Stability/Cost Index of Surgical Techniques Evaluated Under 70-N Protocols

\begin{tabular}{|c|c|c|c|c|c|c|}
\hline Study & $\begin{array}{c}\text { No. } \\
\text { Specimens } \\
\text { (per Group) }\end{array}$ & $\begin{array}{l}\text { Surgical } \\
\text { Techniques }\end{array}$ & Translational Biomechanical Protocol & $\begin{array}{c}\text { Postloading } \\
\text { Translational Testing } \\
\text { Results }(\mathrm{mm}) \text { and RSV }\end{array}$ & $\begin{array}{l}\text { Implants and } \\
\text { Estimated Costs }\end{array}$ & SCI \\
\hline $\begin{array}{l}\text { Hislop et al., }{ }^{43} \\
2019\end{array}$ & $24(8)$ & $\begin{array}{c}\text { (1) } \mathrm{SCT}^{*} \\
\text { (2) } \mathrm{DCT}^{*} \\
\text { (3) } \mathrm{DCT}+\mathrm{AC} \text { suture* }\end{array}$ & $\begin{array}{l}\text { Cyclic loading included anterior, } \\
\text { posterior, and superior translation of } \\
\text { the clavicle relative to the acromion, a } \\
70-\mathrm{N} \text { load was used on all samples } \\
\text { over } 500 \text { cycles at } 1 \mathrm{~Hz} \text {. }\end{array}$ & $\begin{array}{l}\text { (1) A: } 5.01 \pm 1.98 \\
\text { P: } 7.97 \pm 2.71 \\
\text { S: } 13.51 \pm 7.85 \\
\text { RSV: } 228.09 \% \\
\text { (2) A: } 3.36 \pm 1.99 \\
\text { P: } 6.49 \pm 3.86 \\
\text { S: } 11.80 \pm 4.57 \\
\text { RSV: } 279.08 \% . \\
\text { (3) A: } 5.65 \pm 8.42 \\
\text { P: } 9.52 \pm 6.18 \\
\text { S: } 13.36 \pm 4.20 \\
\text { RSV: } 211.78 \% . \\
\text { Control: } \\
\text { A: } 14.17 \pm 8.56 \\
\text { P: } 13.72 \pm 4.18 \\
\text { S: } 12.99 \pm 6.80\end{array}$ & $\begin{array}{l}\text { (1) Two cortical buttons (Dog } \\
\text { Bone; Arthrex), and two 2-mm } \\
\text { suture tapes (FiberTape; } \\
\text { Arthrex). } \\
\text { (2) Three cortical buttons (Dog } \\
\text { Bone; Arthrex), and two 2-mm } \\
\text { suture tapes (FiberTape; } \\
\text { Arthrex). } \\
\text { (3) Three cortical buttons (Dog } \\
\text { Bone; Arthrex), and two 2-mm } \\
\text { suture tapes (FiberTape; } \\
\text { Arthrex). }\end{array}$ & $\begin{array}{l}\text { (1) } 0.671 \\
\text { (2) } 0.657 \\
\text { (3) } 0.498\end{array}$ \\
\hline $\begin{array}{l}\text { Le Hanneur et al., } \\
2018\end{array}$ & $12(6)$ & $\begin{array}{l}\text { (1) Triple-bundle } \\
\text { reconstruction* } \\
\text { (2) Zooker's mWD* }\end{array}$ & $\begin{array}{l}\text { Preconditioning was performed by } \\
\text { cycling the AC joint between } 0 \text { and } 25 \\
\mathrm{~N} \text { over } 10 \text { cycles; the specimens were } \\
\text { then loaded to an amplitude of } 70 \mathrm{~N} \\
\text { over } 1000 \text { cycles at a frequency of } 1 \\
\text { Hz. Displacement at peak force was } \\
\text { documented at } 1 \text { and } 1000 \text { cycles. }\end{array}$ & $\begin{array}{l}\text { (1) A: } 2.80 \pm 0.87 \\
\text { P: } 3.84 \pm 2.50 \\
\text { S: } 2.65 \pm 2.34 \\
\text { RSV: } 278.15 \% . \\
\text { (2) A: } 5.39 \pm 0.94 \\
\text { P: } 14.01 \pm 7.49 \\
\text { S: } 1.33 \pm 0.60 \\
\text { RSV: } 105.09 \% . \\
\text { Control: (1) A: } 4.71 \pm 2.08 \\
\text { P: } 9.14 \pm 4.65 \\
\text { S: } 3.84 \pm 1.42 \\
\text { (2) A: } 3.65 \pm 0.77 \\
\text { P: } 7.99 \pm 4.85 \\
\text { S: } 3.25 \pm 1.40\end{array}$ & $\begin{array}{l}\text { (1) Three no. } 2 \text { sutures } \\
\text { (FiberWire; Arthrex), and three } \\
4 \times 10 \text {-mm interference screws } \\
\text { (Bio-Tenodesis screw; Arthrex). } \\
\text { (2) A no. } 2 \text { suture (FiberWire; } \\
\text { Arthrex), and a 2-cortical } \\
\text { button system (TightRope; } \\
\text { Arthrex). }\end{array}$ & $\begin{array}{l}\text { (1) } 0.364 \\
\text { (2) } 0.271\end{array}$ \\
\hline $\begin{array}{l}\text { Banffy et al., } \\
2018\end{array}$ & $\begin{array}{c}18(9) \\
\text { No a priori power } \\
\text { analysis was } \\
\text { performed }\end{array}$ & $\begin{array}{l}\text { (1) } \mathrm{SCT}^{*} \\
\text { (2) } \mathrm{DCT}^{*}\end{array}$ & $\begin{array}{l}\text { All specimens were conditioned for } 10 \\
\text { cycles to } 25 \mathrm{~N} \text { for anterior-posterior } \\
\text { and superior testing to eliminate creep } \\
\text { phenomenon. The specimens were } \\
\text { then randomly loaded to } 70 \mathrm{~N} \text { in either } \\
\text { the anterior-posterior or superior } \\
\text { direction, with the AC joint, CC } \\
\text { ligaments, and CA ligament intact to } \\
\text { establish baseline displacements for } \\
\text { each specimen. Net displacement } \\
\text { values in the superior, anterior, and } \\
\text { posterior directions were recorded. } \\
\text { Next, the AC and CC ligaments were } \\
\text { completely sectioned. Reconstructions }\end{array}$ & $\begin{array}{l}\text { (1) A: } 4.6 \pm 1.2 \\
\text { P: } 5.1 \pm 1.9 \\
\text { S: } 4.5 \pm 1.9 \\
\text { RSV: } 150.70 \% \\
\text { (2) A: } 6.4 \pm 3.8 \\
\text { P: } 6.5 \pm 3.2 \\
\text { S: } 5.0 \pm 2.0 \\
\text { RSV: } 117.88 \% \\
\text { Control }(1) \text { A: } 4.9 \pm 2.0 \\
\text { P: } 5.8 \pm 3.1 \\
\text { S: } 3.9 \pm 1.7 \\
\text { (2) A: } 5.0 \pm 1.1 \\
\text { P: } 5.7 \pm 2.2 \\
\text { S: } 4.8 \pm 2.3\end{array}$ & $\begin{array}{l}\text { (1) A 1.3-mm suture tape } \\
\text { (SutureTape; Arthrex), a } 5.5 \times \\
\text { 8-mm interference screw } \\
\text { (PEEK Tenodesis Screw; } \\
\text { Arthrex), a cortical button (Dog } \\
\text { Bone; Arthrex), and a } 3.0 \times \\
\text { 14.5-mm suture anchor } \\
\text { (SutureTak; Arthrex). } \\
\text { (2) Two no. } 2 \text { sutures } \\
\text { (FiberWire; Arthrex), a 1.3-mm } \\
\text { suture tape (SutureTape; } \\
\text { Arthrex), two 5.5 } \times 15-\mathrm{mm} \\
\text { interference screws (Bio- } \\
\text { Tenodesis screws; Arthrex), a }\end{array}$ & $\begin{array}{l}\text { (1) } 0.225 \\
\text { (2) } 0.148\end{array}$ \\
\hline
\end{tabular}




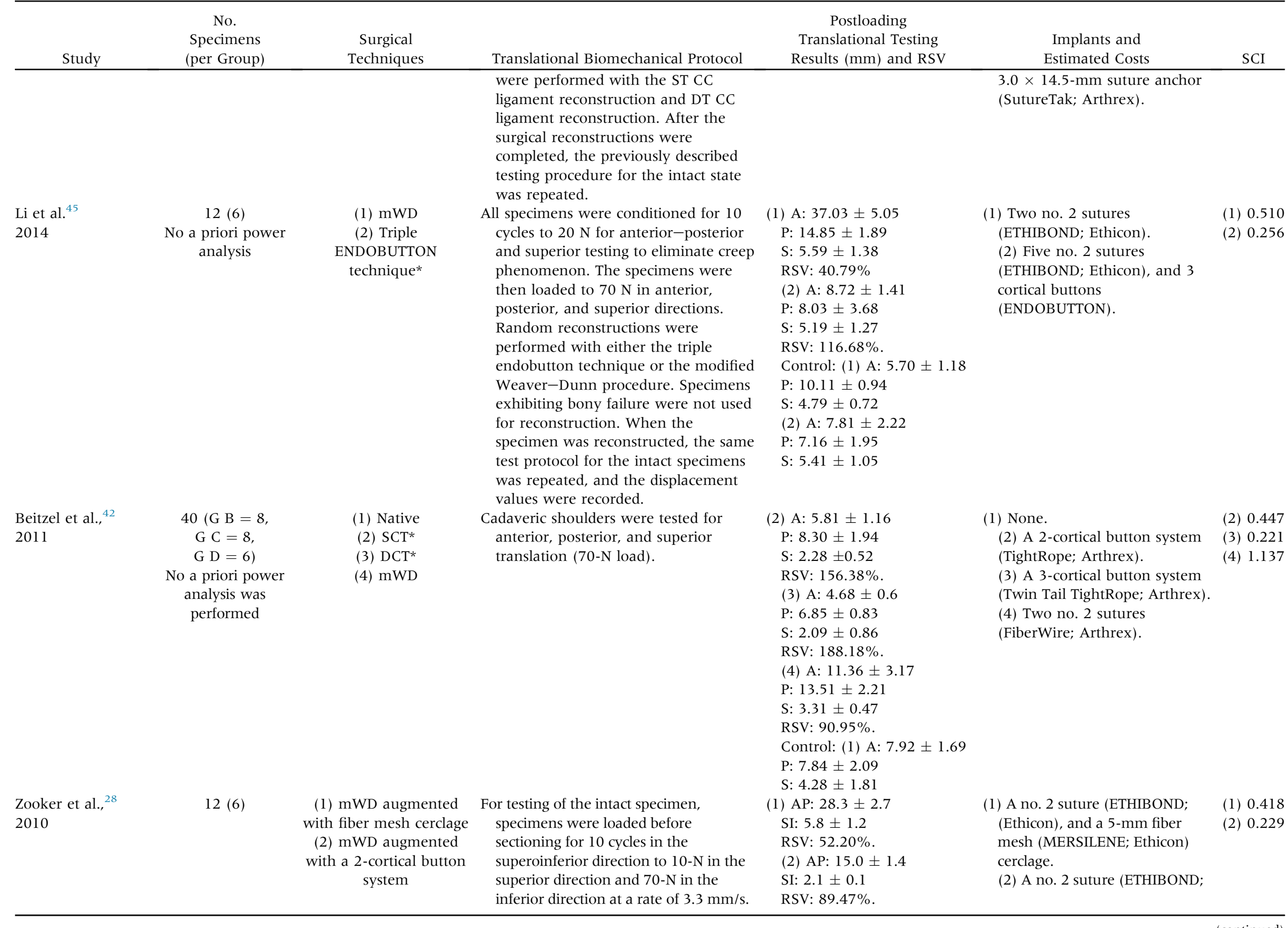


No.

Specimens

Study
Surgical

Techniques
Translational Biomechanical Protocol

Because the coracoid was loaded for

superoinferior loading in this model, superior loading represented inferior movement of the clavicle and inferior loading represented superior movement

of the clavicle. Measurements for the

intact specimen under load were

obtained from the tenth load cycle. A consistent manual load was applied in

both anterior and posterior directions to achieve maximum displacement in the

anteroposterior direction.

After repair, the coracoid of all

specimens was loaded to $10-\mathrm{N}$ in the

superior direction (inferior movement

of the clavicle) and $70 \mathrm{~N}$ in the inferior

direction (superior movement of the

clavicle) for 2000 cycles to simulate early

post-operative loading. Repaired

superoinferior data were obtained from

the first loading cycle after repair and

after 2000 cycles.
Postloading

Translational Testing

Results (mm) and RSV

Implants and

Control: (1) AP: $10.5 \pm 2$.

Estimated Costs

SCI

SI: $4.3 \pm 0.9$

(2) AP: $8.0 \pm 1.1$

SI: $5.4 \pm 0.8$ -cortical button

system (TightRope; Arthrex).

AC, acromioclavicular; CA, coracoacromial; CC, coracoclavicular; DCT, double clavicular tunnel; DT, double tunnel; mWD, modified Weaver-Dunn; P, posterior; RSV, relative stability value; S, superior; SCI, stability/cost index; SCT, single clavicular tunnel; ST, single tunnel.

Techniques denoted with an asterisk $(*)$ exceeded the minimum acceptable threshold of stability. 


\begin{tabular}{|c|c|c|c|c|c|c|}
\hline Study & $\begin{array}{c}\text { No. } \\
\text { Specimens }\end{array}$ & Surgical Techniques & $\begin{array}{l}\text { Superior Direction Load-To-Failure } \\
\text { Protocol }\end{array}$ & $\begin{array}{c}\text { LtF } \\
\text { Results }(\mathrm{N})\end{array}$ & Implants and Estimated Costs & $\begin{array}{l}\text { LtF/Cost } \\
\text { Index }\end{array}$ \\
\hline $\begin{array}{l}\text { Lobao et al., } \\
2020\end{array}$ & $14(7)$ & $\begin{array}{l}\text { (1) Synthetic } \\
\text { ligament technique* } \\
\text { (2) CC suspensory } \\
\text { construct* }^{*}\end{array}$ & $\begin{array}{l}\text { LtF superior tensile test at } 120 \mathrm{~mm} / \mathrm{min} \text {. } \\
\text { To assess } \mathrm{LtF} \text {, the servohydraulic system } \\
\text { was set to monotonically load each } \\
\text { specimen and stop when a drop in force } \\
\text { of } 50 \% \text { from the maximum applied } \\
\text { force was reached. }\end{array}$ & $\begin{array}{l}\text { (1) } 580.5 \\
\text { (2) } 750.2\end{array}$ & $\begin{array}{l}\text { (1) A synthetic ligament (LockDown), a 3.5- } \\
\text { mm cortical screw and a washer. } \\
\text { (2) Two 2-mm suture tapes (FiberTape; } \\
\text { Arthrex). }\end{array}$ & $\begin{array}{l}\text { (1) } 0.726 \\
\text { (2) } 0.413\end{array}$ \\
\hline $\begin{array}{l}\text { Banffy et al. }{ }^{41} \\
2018\end{array}$ & $\begin{array}{l}18(9) \\
\text { No a priori power } \\
\text { analysis was } \\
\text { performed }\end{array}$ & $\begin{array}{l}\text { (1) SCT } \\
\text { (2) DCT }\end{array}$ & $\begin{array}{l}\text { After the surgical reconstructions were } \\
\text { completed, the previously described } \\
\text { testing procedure for the intact state was } \\
\text { repeated, followed by testing to failure } \\
\text { in the superior direction. } \\
\text { No rate for LtF testing shown in the text. } \\
\text { Load-displacement curves were used to } \\
\text { determine the load at failure as the } \\
\text { overall maximum load. }\end{array}$ & $\begin{array}{l}\text { (1) } 398 \\
\text { (2) } 356\end{array}$ & $\begin{array}{l}\text { (1) A 1.3-mm suture tape (SutureTape; } \\
\text { Arthrex), a 5.5 - 8-mm interference } \\
\text { screw (PEEK Tenodesis Screw; Arthrex), a } \\
\text { cortical button (Dog Bone; Arthrex), and a } \\
3.0 \times 14.5 \text {-mm suture anchor (SutureTa; } \\
\text { Arthrex). } \\
\text { (2) Two no. } 2 \text { sutures (FiberWire; } \\
\text { Arthrex), a 1.3-mm suture tape } \\
\text { (SutureTape; Arthrex), two } 5.5 \times 15 \text {-mm } \\
\text { interference screws (Bio-Tenodesis } \\
\text { screws; Arthrex), a 3.0 } \times 14.5 \text {-mm suture } \\
\text { anchor (SutureTak; Arthrex). }\end{array}$ & $\begin{array}{l}\text { (1) } 0.594 \\
\text { (2) } 0.448\end{array}$ \\
\hline $\begin{array}{l}\text { Le Hanneur } \\
\text { et al., }{ }^{44} \\
2018\end{array}$ & $12(6)$ & $\begin{array}{l}\text { (1) Triple-bundle } \\
\text { reconstruction* } \\
\text { (2) Zooker's mWD* }\end{array}$ & $\begin{array}{l}\text { Reconstructed joints were LtF in the } \\
\text { superior direction at a constant } \\
\text { distraction rate of } 1 \mathrm{~mm} / \mathrm{s} \text { to assess the } \\
\text { maximal tensile loading capacity and the } \\
\text { displacement to failure of each } \\
\text { technique; the corresponding stiffness } \\
\text { was calculated from the slope of the } \\
\text { linear region of the force-displacement } \\
\text { curve. } \\
\text { Failure was defined as construct } \\
\text { breakage with interruption of the linear } \\
\text { progression of the slope of the force } \\
\text { - displacement curve. }\end{array}$ & $\begin{array}{l}\text { (1) } 472 \\
\text { (2) } 516\end{array}$ & $\begin{array}{l}\text { (1) Three no. } 2 \text { sutures (FiberWire; } \\
\text { Arthrex), and three } 4 \times 10 \text {-mm } \\
\text { interference screws (Bio-Tenodesis screw, } \\
\text { Arthrex). } \\
\text { (2) A no. } 2 \text { suture (FiberWire; Arthrex), } \\
\text { and a 2-cortical button system (TightRope; } \\
\text { Arthrex). }\end{array}$ & $\begin{array}{l}\text { (1) } 0.617 \\
\text { (2) } 1.323\end{array}$ \\
\hline $\begin{array}{l}\text { Naziri et al. }{ }^{48} \\
2016\end{array}$ & $\begin{array}{l}18(9) \\
\text { No a priori power } \\
\text { analysis was } \\
\text { performed }\end{array}$ & $\begin{array}{l}\text { (1) Reconstruction } \\
\text { using grafts with } \\
\text { UHMWPE suture } \\
\text { ran throughout the } \\
\text { entire length* } \\
\text { (2) Reconstruction } \\
\text { with only native } \\
\text { allografts }\end{array}$ & $\begin{array}{l}\text { Tensile tests were performed using a } \\
\text { mechanical testing machine at a rate of } \\
50 \mathrm{~mm} / \mathrm{min} \text {. A maximum load and } \\
\text { displacement to failure were collected. } \\
\text { Failure was defined at the breaking } \\
\text { point of the failure test curve. }\end{array}$ & $\begin{array}{l}\text { (1) } 437.5 \\
\text { (2) } 94.4\end{array}$ & $\begin{array}{l}\text { (1) A no. } 5 \text { suture (FiberWire; Arthrex), and } \\
\text { two } 5.5 \times 8 \text {-mm interference screws } \\
\text { (PEEK Bio-Tenodesis Screws; Arthrex). } \\
\text { (2) Two } 5.5 \times 8 \text {-mm interference screws } \\
\text { (PEEK Bio-Tenodesis Screws; Arthrex). }\end{array}$ & $\begin{array}{l}\text { (1) } 0.931 \\
\text { (2) } 0.220\end{array}$ \\
\hline
\end{tabular}




\begin{tabular}{|c|c|c|c|c|c|c|}
\hline Study & $\begin{array}{c}\text { No. } \\
\text { Specimens }\end{array}$ & Surgical Techniques & $\begin{array}{l}\text { Superior Direction Load-To-Failure } \\
\text { Protocol } \\
\end{array}$ & $\begin{array}{c}\text { LtF } \\
\text { Results (N) }\end{array}$ & Implants and Estimated Costs & $\begin{array}{l}\text { LtF/Cost } \\
\text { Index } \\
\end{array}$ \\
\hline $\begin{array}{l}\text { Struhl et al. } \\
2016\end{array}$ & $12(6)$ & $\begin{array}{l}\text { (1) Double } \\
\text { ENDOBUTTON } \\
\text { construct* } \\
\text { (2) Dog Bone } \\
\text { button construct* }\end{array}$ & $\begin{array}{l}\text { LtF testing was performed at a rate of } 1 \\
\text { mm/s in the superior direction, and } \\
\text { load-displacement curves were } \\
\text { obtained. } \\
\text { Failure was defined as a } 10 \text {-mm superior } \\
\text { displacement or any fracture, } \\
\text { insufficiency, or material incompetence. }\end{array}$ & $\begin{array}{l}\text { (1) } 558 \\
\text { (2) } 552\end{array}$ & $\begin{array}{l}\text { (1) A 2-cortical button system } \\
\text { (ENDOBUTTON CL system; Smith \& } \\
\text { Nephew), and a no. } 5 \text { suture (ETHIBOND; } \\
\text { Ethicon). } \\
\text { (2) A 2-cortical button system (Dog Bone; } \\
\text { Arthrex). }\end{array}$ & $\begin{array}{ll}\text { (1) } & 1.431 \\
\text { (2) } & 1.577\end{array}$ \\
\hline $\begin{array}{l}\text { Abat et al., } \\
2015\end{array}$ & $\begin{array}{l}18(9) \\
\text { No a priori power } \\
\text { analysis was } \\
\text { performed }\end{array}$ & $\begin{array}{l}\text { (1) Control } \\
\text { (2) DCT* } \\
\text { (3) Repair in a "V" } \\
\text { configuration with } \\
\text { 2tunnels in the } \\
\text { clavicle and one in } \\
\text { the coracoid }\end{array}$ & $\begin{array}{l}\text { The traction test was performed at a speed } \\
\text { of } 15 \mathrm{~mm} / \mathrm{min} \text {. Pretensioning was } \\
\text { performed at } 15 \mathrm{~N} \text { before the } \\
\text { displacement of the bar of the testing } \\
\text { machine was initiated. The test was } \\
\text { stopped when the tensile force dropped } \\
\text { by } 60 \% \text { of the maximum applied force } \\
\text { (Fmax } 60 \% \text { ) or when the mobility of the } \\
\text { part or implant failure was observed. In } \\
\text { each test, the maximum breaking force } \\
\text { (in N) was obtained. }\end{array}$ & $\begin{array}{l}\text { (1) } 444.0 \\
\text { (2) } 495.6 \\
\text { (3) } 343.9\end{array}$ & $\begin{array}{l}\text { (1) Native. } \\
\text { (2) Two 2-cortical button system } \\
\text { (ZipTight; Biomet). } \\
\text { (3) A 2-cortical button system (ZipTight; } \\
\text { Biomet). }\end{array}$ & $\begin{array}{l}\text { (2) } 0.708 \\
\text { (3) } 0.983\end{array}$ \\
\hline $\begin{array}{l}\text { Weiser et al., } \\
2015\end{array}$ & $24(6)$ & $\begin{array}{l}\text { (1) Double TR* } \\
\text { (2) Double TR with } \\
\text { AC repair* (3) } \\
\text { Single TR with AC } \\
\text { repair* } \\
\text { (4) PDS sling with } \\
\text { AC repair* }\end{array}$ & $\begin{array}{l}\text { Vertical LtF } 25 \mathrm{~mm} / \mathrm{min} \text { determined after } \\
\text { cyclic testing. } \\
\text { Failure was defined as a vertical } \\
\text { dislocation of more than } 20 \mathrm{~mm} \text {, or any } \\
\text { fracture, insufficiency, or material } \\
\text { failure. }\end{array}$ & $\begin{array}{l}\text { (1) } 884.4 \\
\text { (2) } 846.8 \\
\text { (3) } 708.0 \\
\text { (4) } 767.0\end{array}$ & $\begin{array}{l}\text { (1) Two 2-cortical button systems } \\
\text { (TightRope; Arthrex). } \\
\text { (2) Two 2-cortical button systems } \\
\text { (TightRope; Arthrex) and a 3-mm suture } \\
\text { tape (PDS; Ethicon). } \\
\text { (3) A 2-cortical button system (TightRope; } \\
\text { Arthrex) and a 3-mm suture tape (PDS; } \\
\text { Ethicon). } \\
\text { (4) A 5-mm suture tape (PDS; Ethicon) } \\
\text { and a 3-mm suture tape (PDS; Ethicon). }\end{array}$ & $\begin{array}{l}\text { (1) } 1.263 \\
\text { (2) } 1.079 \\
\text { (3) } 1.628 \\
\text { (4) } 4.512\end{array}$ \\
\hline $\begin{array}{l}\text { Grantham } \\
\text { et al.,. } \\
2016\end{array}$ & $\begin{array}{l}16(8) \\
\text { No a priori power } \\
\text { analysis was } \\
\text { performed }\end{array}$ & $\begin{array}{l}\text { (1) Double } \\
\text { endobutton } \\
\text { technique using a 2- } \\
\text { cortical button } \\
\text { system* } \\
\text { (2) Coracoid } \\
\text { cerclage sling }\end{array}$ & $\begin{array}{l}\text { LtF characteristics of the reconstruction } \\
\text { were measured by mounting the } \\
\text { shoulder onto a material testing } \\
\text { machine. The clavicle was fixed to the } \\
\text { Instron crosshead with a fixed load cell, } \\
\text { and the specimen was pulled in a } \\
\text { superior direction at a rate of } 50 \mathrm{~mm} / \\
\text { min. }\end{array}$ & $\begin{array}{l}\text { (1) } 448.4 \\
\text { (2) } 226.9\end{array}$ & $\begin{array}{l}\text { (1) A 2-cortical button system } \\
\text { (ENDOBUTTON CL system; Smith \& } \\
\text { Nephew), and a no. } 5 \text { suture (ETHIBOND; } \\
\text { Ethicon). } \\
\text { (2) Three no. } 2 \text { sutures (FiberWire; } \\
\text { Arthrex). }\end{array}$ & $\begin{array}{l}\text { (1) } 1.150 \\
\text { (2) } 1.891\end{array}$ \\
\hline $\begin{array}{l}\text { Li et al. }{ }^{45} \\
2014\end{array}$ & $\begin{array}{l}12(6) \\
\text { No a priori power } \\
\text { analysis was } \\
\text { performed }\end{array}$ & $\begin{array}{l}\text { (1) mWD } \\
\text { (2) Triple } \\
\text { Endobutton } \\
\text { technique* }\end{array}$ & $\begin{array}{l}\mathrm{LtF} \text { test followed at } 25 \mathrm{~mm} / \mathrm{min} \text { in the } \\
\text { superior direction to simulate AC joint } \\
\text { dislocation. } \\
\text { No failure definition. }\end{array}$ & $\begin{array}{l}\text { (1) (1) } 171.64 \\
\text { (2) } 686.88\end{array}$ & $\begin{array}{l}\text { (1) Two no. } 2 \text { sutures (ETHIBOND; Ethicon) } \\
\text { (2) Five no. } 2 \text { sutures (ETHIBOND; } \\
\text { Ethicon), and } 3 \text { cortical buttons } \\
\text { (ENDOBUTTON). }\end{array}$ & $\begin{array}{l}\text { (1) } 2.146 \\
\text { (2) } 1.510\end{array}$ \\
\hline
\end{tabular}




\begin{tabular}{|c|c|c|c|c|c|c|}
\hline Study & $\begin{array}{c}\text { No. } \\
\text { Specimens }\end{array}$ & Surgical Techniques & $\begin{array}{l}\text { Superior Direction Load-To-Failure } \\
\text { Protocol }\end{array}$ & $\begin{array}{c}\text { LtF } \\
\text { Results }(\mathrm{N})\end{array}$ & Implants and Estimated Costs & $\begin{array}{l}\text { LtF/Cost } \\
\text { Index }\end{array}$ \\
\hline $\begin{array}{l}\text { Martetschläger } \\
\text { et al., } 51 \\
2013\end{array}$ & $\begin{array}{l}24(12) \\
\text { No a priori power } \\
\text { analysis was } \\
\text { performed }\end{array}$ & $\begin{array}{l}\text { (1) Native } \\
\text { (2) PDS cerclage } \\
\text { reconstruction* }\end{array}$ & $\begin{array}{l}\text { LtF, stiffness and elongation at LtF and } \\
\text { failure mode were evaluated. LtF was } \\
\text { considered when the testing machine } \\
\text { stopped at a drop in force of } 50 \% \text { from } \\
\text { the applied maximum force (Fmax } \\
50 \% \text { ). The recorded Fmax was equated } \\
\text { with the LtF. } \\
\text { Clinical failure was defined as } \\
\text { elongation of } 12 \mathrm{~mm} \text { (ca. } 1 \text { mm less than } \\
\text { elongation at failure of the native } \\
\text { ligaments). }\end{array}$ & $\begin{array}{l}\text { (1) } 590.1 \\
\text { (2) } 569.9\end{array}$ & $\begin{array}{l}\text { (1) Native. } \\
\text { (2) Two } 1.5 \text {-mm braided cord cerclages } \\
\text { (PDS; Ethicon), and a 1.0-mm braided } \\
\text { cord (PDS; Ethicon). }\end{array}$ & (2) 2.235 \\
\hline $\begin{array}{l}\text { Nüchtern } \\
\text { et al. }^{52} \\
2013\end{array}$ & $\begin{array}{l}18(6) \\
\text { No a priori power } \\
\text { analysis was } \\
\text { performed }\end{array}$ & $\begin{array}{l}\text { (1) Locking hook } \\
\text { plate } \\
\text { (2) TR* c) Bone } \\
\text { anchor systems* }\end{array}$ & $\begin{array}{l}\text { LtF testing was performed using a static } \\
\text { increasing axial load at a rate of } 25 \mathrm{~mm} / \\
\text { min. Failure was defined as a } 20-\mathrm{mm} \\
\text { superior dislocation or any fracture, } \\
\text { insufficiency, or material failure } \\
\text { occurrence. Photographic and } \\
\text { radiographic documentation was } \\
\text { obtained in every case. }\end{array}$ & $\begin{array}{l}\text { (1) } 248.9 \\
\text { (2) } 832.0 \\
\text { (3) } 538.0\end{array}$ & $\begin{array}{l}\text { (1) Locking hook plate (LCP Hook Plate; } \\
\text { Synthes). } \\
\text { (2) Two 2-cortical button systems } \\
\text { (TightRope; Arthrex). c) Two 6.5-mm } \\
\text { suture anchors (Corkscrew anchors; } \\
\text { Arthrex), and } 2 \text { cortical buttons (small } \\
\text { plates). }\end{array}$ & $\begin{array}{l}\text { (1) } 0.332 \\
\text { (2) } 1.189 \\
\text { (3) } 0.727\end{array}$ \\
\hline $\begin{array}{l}\text { Shin et al. } \\
2014\end{array}$ & $12(6)$ & $\begin{array}{l}\text { (1) Single tendon } \\
\text { anatomic AC-CC } \\
\text { reconstruction* } \\
\text { (2) Coracoid } \\
\text { cerclage } \\
\text { reconstruction }\end{array}$ & $\begin{array}{l}\mathrm{LtF} \text { at } 50 \mathrm{~mm} / \mathrm{min} \text {. The direction of load } \\
\text { corresponded to superior clavicle } \\
\text { translation. } \\
\text { No failure definition. }\end{array}$ & $\begin{array}{l}\text { (1) } 443.2 \\
\text { (2) } 295.4\end{array}$ & $\begin{array}{l}\text { (1) Three no. } 2 \text { FiberWire (Arthrex), } 14 \times \\
\text { 3.5-mm 2-cortical button system } \\
\text { (GraftRope; Arthrex), and } 4.75-\mathrm{mm} \text { and } \\
\text { 5.5-mm interference screws (Bio- } \\
\text { Tenodesis screw; Arthrex). } \\
\text { (2) Two no. } 2 \text { sutures (FiberWire; } \\
\text { Arthrex), Two } 4.5 \text {-mm interference screw } \\
\text { (Bio-Tenodesis screw; Arthrex). }\end{array}$ & $\begin{array}{l}\text { (1) } 0.492 \\
\text { (2) } 0.579\end{array}$ \\
\hline $\begin{array}{l}\text { Staron et al. } \\
2013\end{array}$ & $16(8)$ & $\begin{array}{l}\text { (1) Lee's modified } \\
\text { knot fixation } \\
\text { technique } \\
\text { (2) Mazzocca's } \\
\text { modified anatomical } \\
\text { double-bundle } \\
\text { technique with } \\
\text { interference screws }\end{array}$ & $\begin{array}{l}\text { The intact CC ligaments were tested to } \\
\text { failure with superior displacement at a } \\
\text { rate of } 2 \mathrm{~mm} / \mathrm{s} \text {. Reconstruction was } \\
\text { performed using a semitendinosus } \\
\text { tendon allograft, and LtF was repeated } \\
\text { for each construct. } \\
\text { Failure was defined as } 2 \mathrm{~cm} \text { of } \\
\text { displacement, which is approximately } \\
\text { the amount of displacement of a grade } 3 \\
\text { acromioclavicular separation. }\end{array}$ & $\begin{array}{l}\text { (1) } 347.5 \\
\text { (2) } 326.9\end{array}$ & $\begin{array}{l}\text { (1) Three no. } 2 \text { sutures (FiberWire; } \\
\text { Arthrex). } \\
\text { (2) Two no. } 2 \text { sutures (FiberWire; } \\
\text { Arthrex), and two } 5.5 \times 15 \text {-mm } \\
\text { interference screws (Bio-Tenodesis screw; } \\
\text { Arthrex). }\end{array}$ & $\begin{array}{l}\text { (1) } 2.896 \\
\text { (2) } 0.641\end{array}$ \\
\hline
\end{tabular}




\begin{tabular}{|c|c|c|c|c|c|c|}
\hline Study & $\begin{array}{c}\text { No. } \\
\text { Specimens }\end{array}$ & Surgical Techniques & $\begin{array}{l}\text { Superior Direction Load-To-Failure } \\
\text { Protocol }\end{array}$ & $\begin{array}{c}\text { LtF } \\
\text { Results (N) }\end{array}$ & Implants and Estimated Costs & $\begin{array}{l}\mathrm{LtF} / \mathrm{Cost} \\
\text { Index }\end{array}$ \\
\hline $\begin{array}{l}\text { Tashjian } \\
\text { et al., } \\
2012\end{array}$ & 8 & $\begin{array}{l}\text { (1) Interference } \\
\text { screw fixation } \\
\text { method* } \\
\text { (2) Side-to-side } \\
\text { suturing } \\
\text { (3) Square knot* }\end{array}$ & $\begin{array}{l}\text { LtF testing was performed on each } \\
\text { construct. Using position control, } \\
\text { mechanical testing of each specimen } \\
\text { was performed by moving the clavicle in } \\
\text { a superior direction at a constant } \\
\text { displacement rate of } 25 \mathrm{~mm} / \mathrm{min} \text { while } \\
\text { continuously recording displacement } \\
\text { and load. Ultimate failure was defined as } \\
\text { the first significant decrease in load seen } \\
\text { on the load-displacement graph. }\end{array}$ & $\begin{array}{l}\text { (1) } 469.7 \\
\text { (2) } 510.7 \\
\text { (3) } 614.8\end{array}$ & $\begin{array}{l}\text { (1) Two } 5.5 \times 25 \text {-mm interference screws } \\
\text { (PEEK Bio-Tenodesis screws; Arthrex). } \\
\text { (2) A no. } 2 \text { suture (FiberWire; Arthrex). } \\
\text { (3) A no. } 2 \text { suture (FiberWire; Arthrex). }\end{array}$ & $\begin{array}{l}\text { (1) } 1.092 \\
\text { (2) } 12.768 \\
\text { (3) } 15.370\end{array}$ \\
\hline $\begin{array}{l}\text { Beitzel et al., } \\
2011\end{array}$ & $\begin{array}{c}40(\mathrm{G} \mathrm{B}=8, \\
\mathrm{G} \mathrm{C}=8, \\
\mathrm{G} \mathrm{D}=6) \\
\text { No a priori power } \\
\text { analysis was } \\
\text { performed }\end{array}$ & $\begin{array}{l}\text { (1) Native } \\
\text { (2) } \mathrm{SCT}^{*} \\
\left.\text { (3) } \mathrm{DCT}^{*} \mathrm{~d}\right) \mathrm{mWD}\end{array}$ & $\begin{array}{l}\text { LtF testing }(120 \mathrm{~mm} / \mathrm{min}) \text { was then } \\
\text { performed in a superior direction to } \\
\text { evaluate the maximal loading capacity } \\
\text { of the reconstruction. } \\
\text { No failure definition. }\end{array}$ & $\begin{array}{l}\text { (2) } 591.35 \\
\text { (3) } 651.16 \\
\text { (4) } 311.13 \\
\text { Control: (1) } 579.44\end{array}$ & $\begin{array}{l}\text { (1) None. } \\
\text { (2) A 2-cortical button system (TightRope; } \\
\text { Arthrex). } \\
\text { (3) A 3-cortical button system (Twin Tail } \\
\text { TightRope; Arthrex). d) Two no. } 2 \text { sutures } \\
\text { (FiberWire; Arthrex). }\end{array}$ & $\begin{array}{l}\text { (1) } 1.690 \\
\text { (2) } 0.766 \\
\text { (3) } 3.889\end{array}$ \\
\hline $\begin{array}{l}\text { Clevenger } \\
\text { et al., } 53 \\
2011\end{array}$ & $14(7)$ & $\begin{array}{c}\text { (1) Hamstring } \\
\text { allograft CC } \\
\text { reconstruction* (2) } \\
\text { Hamstring allograft } \\
\text { CC reconstruction } \\
\text { plus a CA ligament } \\
\text { transfer* }\end{array}$ & $\begin{array}{l}\text { LtF testing was added to the protocol after } \\
\text { the initial } 4 \text { specimens had been tested } \\
\text { and were, therefore, performed on } 10 \text { of } \\
\text { the specimens, independent of the } \\
\text { reconstruction technique used. Using } \\
\text { position control, we performed } \\
\text { mechanical testing of each specimen by } \\
\text { moving the clavicle in a superior } \\
\text { direction at a constant displacement rate } \\
\text { of } 25 \mathrm{~mm} / \text { min while continuously } \\
\text { recording displacement and load. } \\
\text { Ultimate failure was defined as the first } \\
\text { significant decrease in load seen on the } \\
\text { load-displacement graph. }\end{array}$ & $\begin{array}{l}\text { (1) } 970.3 \\
\text { (2) } 952.7\end{array}$ & $\begin{array}{l}\text { (1) Two no. } 5 \text { sutures, and a no. } 2 \text { suture } \\
\text { (FiberWire; Arthrex). } \\
\text { (2) Two } \mathrm{N}^{\circ} 5 \text { sutures, and two } \mathrm{N}^{\circ} 2 \\
\text { sutures (FiberWire; Arthrex). }\end{array}$ & $\begin{array}{l}\text { (1) } 8.086 \\
\text { (2) } 5.954\end{array}$ \\
\hline
\end{tabular}

polydioxanone; SCT, single clavicular tunnel; TR, TightRope; UHMWPE, ultra-high molecular-weight polyethylene.

Techniques denoted with an asterisk $\left(^{*}\right)$ exceeded the minimum acceptable threshold of load to-failure. 
Table 5. STROBE Statement Checklist Score of Included Studies

\begin{tabular}{|c|c|c|}
\hline Study & Year & Score (max. 32) \\
\hline Zooker et al. $^{28}$ & 2010 & 29 \\
\hline Beitzel et al. ${ }^{42}$ & 2011 & 28 \\
\hline Clevenger et al. ${ }^{53}$ & 2011 & 29 \\
\hline Tashjian et al. ${ }^{31}$ & 2012 & 29 \\
\hline Staron et al. ${ }^{54}$ & 2013 & 30 \\
\hline Shin et al. ${ }^{30}$ & 2014 & 30 \\
\hline Nüchtern et al. ${ }^{54}$ & 2013 & 28 \\
\hline Martetschläger et al. ${ }^{51}$ & 2013 & 28 \\
\hline Li et al. ${ }^{45}$ & 2014 & 28 \\
\hline Grantham et al. ${ }^{23}$ & 2016 & 28 \\
\hline Weiser et al. ${ }^{50}$ & 2015 & 29 \\
\hline Abat et al. ${ }^{49}$ & 2015 & 29 \\
\hline Naziri et al. ${ }^{48}$ & 2016 & 29 \\
\hline Struhl et al. ${ }^{47}$ & 2016 & 31 \\
\hline Banffy et al. ${ }^{41}$ & 2018 & 28 \\
\hline Le Hanneur et al. ${ }^{44}$ & 2018 & 31 \\
\hline Hislop et al. ${ }^{43}$ & 2019 & 29 \\
\hline Lobao et al. ${ }^{46}$ & 2020 & 31 \\
\hline
\end{tabular}

the conservative group in exchange for cosmesis. ${ }^{14,15} \mathrm{It}$ is important to highlight that choosing conservative treatment as the initial option will not jeopardize clinical outcome if surgical treatment is subsequently needed. ${ }^{4}$ To date, the percentage of conservative treatment failures related to associated injuries in AC joint dislocations is unknown, but Ruiz Ibán et al. ${ }^{60}$ have reported 1 in every 5 patients undergoing surgical treatment to fail based on a meta-analysis of 21 studies.

Meta-analysis of biomechanical studies in the last decade and available evidence shows greater SCI in non-ACCR surgical techniques of AC joint dislocations. Non-ACCR techniques, or techniques combining 2 clavicular tunnels separated by at least $10 \mathrm{~mm}$, a mean of 2 sutures, and/or suture tapes provide supraphysiologic stability and load-to-failure in controlled biomechanical testing. In addition, they show the greatest SCI and LtFCI when considering implant costs.

\section{Limitations}

There are some limitations to this study that should be noted. First, a high degree of heterogeneity exists in the included studies. Different preconditioning protocols, cycles, and frequency of loading, load-to-failure rates, and failure definitions were found. However, the direction and quantity of mechanical loading in each study were similar. Second, our study does not consider rotational stability that may play an essential role in the outcome. ${ }^{9,32}$

Third, the sample size in the included biomechanical studies comparing non-ACCR versus ACCR techniques was limited to 5 studies for 3 -direction $70-\mathrm{N}$ protocols and 7 studies for load-to-failure protocols, for a total of 16 techniques of 41 assessed in the SCI and LtFCI analysis (18 studies). However, the differences between the 2 groups were statistically significant. Lastly, the standardization of the cost of implants may modify the SCI and LtFCI of specific techniques. Special attention was taken to preserve the price ratio between the type of implants, which could potentially alter the indexes rather than values themselves. We recognize that the cost of ACCR techniques involving the use of grafts is underestimated in our calculations. Autograft tissue can be used; however, this adds surgical time and cost for graft harvest and preparation, and there is accompanying patient morbidity. Allograft tissue avoids harvest time and morbidity; however, there is a significant additional cost for allograft tissue (around \$2775). ${ }^{61}$ Accounting for the graft cost would result in an even lower SCI and LtFCI value for ACCR techniques. It is important to state that graft implementation's biological benefits cannot be evaluated in biomechanical studies, especially in chronic injuries where the native ligament' healing potential is impaired. ${ }^{5,6,10,21}$ However, graft implementation has shown greater early elongation than suture constructs, ${ }^{23,31,48,53,54}$ which show no relevant creep or stretching after 100-500 cycles and are potentially relevant in the acute setting. ${ }^{43,53}$ In addition, all but 3 of the included studies used implants from the same manufacturing company.

Future research in cost-effectiveness will bring new perspectives in the treatment of AC joint dislocations. It is unknown how much stability is needed to provide clinical benefits, and when additional biomechanical stability fails to provide additional clinically relevant improvement, it results in higher costs. Nevertheless, excellent and comparable clinical subjective outcome

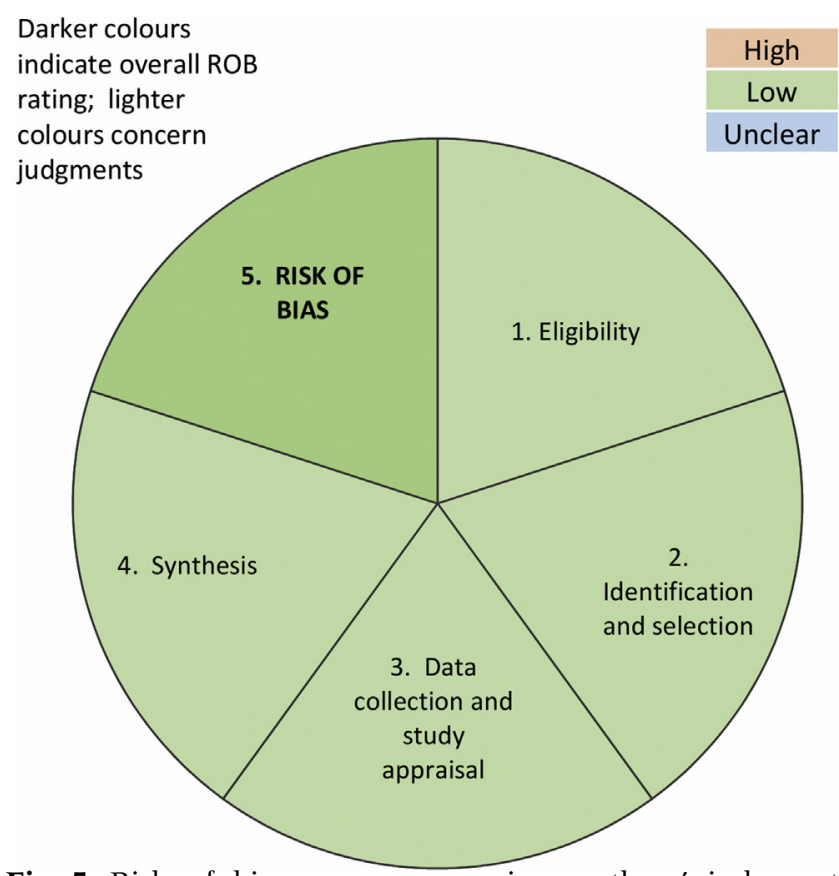

Fig 5. Risk of bias summary: review authors' judgments about each risk of bias using ROBIS tool. (ROB, risk of bias.) 
scores suggest that any technique provides acceptable results for most patients.

\section{Conclusions}

Non-ACCR and ACCR techniques exceeded the minimum acceptable threshold of stability and failure loads in controlled biomechanical testing. However, non-ACCR and techniques combining two clavicular tunnels separated by at least $10 \mathrm{~mm}$, a mean of $2 \mathrm{su}$ tures and/or suture tapes provide supraphysiologic stability and failure loads at a lower cost of implants.

\section{Acknowledgments}

The authors thank Pr. Dr. Olufemi R. Ayeni for his comments on the final version of the manuscript.

\section{References}

1. Skjaker SA, Enger M, Engebretsen L, Brox JI, Bøe B. Young men in sports are at highest risk of acromioclavicular joint injuries: A prospective cohort study [published online April 8, 2020]. Knee Surg Sports Traumatol Arthrosc. https://doi.org/10.1007/s00167-020-05958-x.

2. Frantz T, Ramkumar PN, Frangiamore S, et al. Epidemiology of acromioclavicular joint injuries in professional baseball: Analysis from the Major League Baseball Health and Injury Tracking System. J Shoulder Elbow Surg 2021;30:127-133.

3. Nordin JS, Olsson O, Lunsjö K. Acromioclavicular joint dislocations: Incidence, injury profile, and patient characteristics from a prospective case series. JSES Int 2020;4: 246-250.

4. Gowd AK, Liu JN, Cabarcas BC, et al. Current concepts in the operative management of acromioclavicular dislocations: A systematic review and meta-analysis of operative techniques. Am J Sports Med 2019;47:2745-2758.

5. Frank RM, Cotter EJ, Leroux TS, Romeo AA. acromioclavicular joint injuries: Evidence-based treatment. J Am Acad Orthop Surg 2019;27:e775-e788.

6. Phadke A, Bakti N, Bawale R, Singh B. Current concepts in management of ACJ injuries. J Clin Orthop Trauma 2019;10:480-485.

7. Flores DV, Goes PK, Gómez CM, Umpire DF, Pathria MN. Imaging of the acromioclavicular joint: Anatomy, function, pathologic features, and treatment. Radiographics 2020;40:1355-1382.

8. Lee J, El-Daou H, Alkoheji M, Carlos A, Di Mascio L, Amis A. Ligamentous and capsular restraints to anterior posterior and superior inferior laxity of the acromioclavicular joint-a biomechanical study [published online September 30, 2020]. J Shoulder Elbow Surg. https://doi.org/10.1016/j.jse. 2020.09.006.

9. Dyrna FGE, Imhoff FB, Voss A, et al. The integrity of the acromioclavicular capsule ensures physiological centering of the acromioclavicular joint under rotational loading. Am J Sports Med 2018;46:1432-1440.

10. Borbas P, Churchill J, Ek ET. Surgical management of chronic high-grade acromioclavicular joint dislocations: A systematic review. J Shoulder Elbow Surg 2019;28: 2031-2038.

11. Putnam M, Vanderkarr M, Nandwani P, Holy CE, Chitnis AS. Surgical treatment, complications, and reimbursement among patients with clavicle fracture and acromioclavicular dislocations: a US retrospective claims database analysis. J Med Econ 2019;22:901-908.

12. Arirachakaran A, Boonard M, Piyapittayanun P, Phiphobmongkol V, Chaijenkij K, Kongtharvonskul J. Comparison of surgical outcomes between fixation with hook plate and loop suspensory fixation for acute unstable acromioclavicular joint dislocation: A systematic review and meta-analysis. Eur J Orthop Surg Traumatol 2016;26: 565-574.

13. Arirachakaran A, Boonard M, Piyapittayanun P, et al. Post-operative outcomes and complications of suspensory loop fixation device versus hook plate in acute unstable acromioclavicular joint dislocation: A systematic review and meta-analysis. J Orthop Traumatol 2017;18:293-304.

14. Chang N, Furey A, Kurdin A. Operative versus nonoperative management of acute high-grade acromioclavicular dislocations: A systematic review and meta-analysis. J Orthop Trauma 2018;32:1-9.

15. Tamaoki MJS, Lenza M, Matsunaga FT, Belloti J, Matsumoto MH, Faloppa F. Surgical versus conservative interventions for treating acromioclavicular dislocation of the shoulder in adults. Cochrane Database Syst Rev 2019;10: CD007429.

16. Longo UG, Ciuffreda M, Rizzello G, Mannering N, Maffulli N, Denaro V. Surgical versus conservative management of Type III acromioclavicular dislocation: A systematic review. Br Med Bull 2017;122:31-49.

17. Tracking universal health coverage: 2017 global monitoring report. Geneva: World Health Organization and International Bank for Reconstruction and Development/The World Bank, 2017.

18. Kay J, Memon M, Alolabi B. Return to sport and clinical outcomes after surgical management of acromioclavicular joint dislocation: A systematic review. Arthroscopy 2018;34:2910-2924.el.

19. Schär MO, Jenni S, Fessel G, Snedeker JG, Scheibel M, Zumstein MA. Biomechanical comparison of two biplanar and one monoplanar reconstruction techniques of the acromioclavicular joint. Arch Orthop Trauma Surg 2019;139:779-786.

20. Mazzocca AD, Santangelo SA, Johnson ST, Rios CG, Dumonski ML, Arciero RA. A biomechanical evaluation of an anatomical coracoclavicular ligament reconstruction. Am J Sports Med 2006;34:236-246.

21. Moatshe G, Kruckeberg BM, Chahla J, et al. Acromioclavicular and coracoclavicular ligament reconstruction for acromioclavicular joint instability: A systematic review of clinical and radiographic outcomes. Arthroscopy 2018;34:1979-1995.e8.

22. Spencer HT, Hsu L, Sodl J, Arianjam A, Yian EH. Radiographic failure and rates of reoperation after acromioclavicular joint reconstruction: A comparison of surgical techniques. Bone Joint J 2016;98-B:512-518.

23. Grantham C, Heckmann N, Wang L, Tibone JE, Struhl S, Lee TQ. A biomechanical assessment of a novel double ENDOBUTTON technique versus a coracoid cerclage sling 
for acromioclavicular and coracoclavicular injuries. Knee Surg Sports Traumatol Arthrosc 2016;24:1918-1924.

24. Jordan RW, Malik S, Bentick K, Saithna A. Acromioclavicular joint augmentation at the time of coracoclavicular ligament reconstruction fails to improve functional outcomes despite significantly improved horizontal stability. Knee Surg Sports Traumatol Arthrosc 2019;27:3747-3763.

25. Theopold J, Schöbel T, Fischer JP, et al. Acromioclavicular joint reconstruction: An additional acromioclavicular cerclage does not improve horizontal stability in double coraco-clavicular tunnel technique. Knee Surg Sports Traumatol Arthrosc 2019;27:3827-3834.

26. Xará-Leite F, Andrade R, Moreira PS, et al. Anatomic and non-anatomic reconstruction improves post-operative outcomes in chronic acromio-clavicular instability: A systematic review. Knee Surg Sports Traumatol Arthrosc 2019;27:3779-3796.

27. Vrgoč G, Japjec M, Jurina P, et al. Operative treatment of acute acromioclavicular dislocations Rockwood III and VComparative study between K-wires combined with FiberTape ${ }^{\circledR}$ vs. TightRope System ${ }^{\circledR}$. Injury 2015;46: S107-S112 (suppl 6).

28. Zooker CC, Parks BG, White KL, Hinton RY. TightRope versus fiber mesh tape augmentation of acromioclavicular joint reconstruction: A biomechanical study. Am J Sports Med 2010;38:1204-1208.

29. Frank RM, Trenhaile SW. Arthroscopic-assisted acromioclavicular joint reconstruction using the TightRope device with allograft augmentation: Surgical technique. Arthrosc Tech 2015;4:e293-e297.

30. Shin SJ, Campbell S, Scott J, McGarry MH, Lee TQ. Simultaneous anatomic reconstruction of the acromioclavicular and coracoclavicular ligaments using a single tendon graft. Knee Surg Sports Traumatol Arthrosc 2014;22: 2216-2222.

31. Tashjian RZ, Southam JD, Clevenger T, Bachus KN. Biomechanical evaluation of graft fixation techniques for acromioclavicular joint reconstructions using coracoclavicular tendon grafts. J Shoulder Elbow Surg 2012;21: 1573-1579.

32. Morikawa D, Mazzocca AD, Obopilwe E, et al. Reconstruction of the acromioclavicular ligament complex using dermal allograft: A biomechanical analysis. Arthroscopy 2020;36:108-115.

33. Horst K, Dienstknecht T, Pishnamaz M, Sellei RM, Kobbe P, Pape HC. Operative treatment of acute acromioclavicular joint injuries graded Rockwood III and IV: Risks and benefits in tight rope technique vs. k-wire fixation. Patient Saf Surg 2013;7:18.

34. Yin J, Yin Z, Gong G, Zhu C, Sun C, Liu X. Comparison of hook plate with versus without double-tunnel coracoclavicular ligament reconstruction for repair of acute acromioclavicular joint dislocations: A prospective randomized controlled clinical trial. Int J Surg 2018;54:18-23.

35. Chernchujit B, Parate P. Surgical technique for arthroscopyassisted anatomical reconstruction of acromioclavicular and coracoclavicular ligaments using autologous hamstring graft in chronic acromioclavicular joint dislocations. Arthrosc Tech 2017; 6:e641-e648.

36. Athar MS, Ashwood N, Arealis G, Hamlet M, Salt E. Acromioclavicular joint disruptions: A comparison of two surgical approaches 'hook' and 'rope'. J Orthop Surg (Hong Kong) 2018;26:2309499017749984.

37. Abdelrahman AA, Ibrahim A, Abdelghaffar K, Ghandour TM, Eldib D. Open versus modified arthroscopic treatment of acute acromioclavicular dislocation using a single tight rope: Randomized comparative study of clinical outcome and cost-effectiveness. J Shoulder Elbow Surg 2019;28:2090-2097.

38. Mazzocca AD, Spang JT, Rodriguez RR, et al. Biomechanical and radiographic analysis of partial coracoclavicular ligament injuries. Am J Sports Med 2008;36: 1397-1402.

39. Beitzel K, Cote MP, Apostolakos J, et al. Current concepts in the treatment of acromioclavicular joint dislocations. Arthroscopy 2013;29:387-397.

40. Wallace BC, Dahabreh IJ, Trikalinos TA, Lau J, Trow P, Schmid CH. Closing the gap between methodologists and end-users: R as a computational back-end. J Stat Software 2012;49:5.

41. Banffy MB, Uquillas C, Neumann JA, ElAttrache NS. Biomechanical evaluation of a single- versus doubletunnel coracoclavicular ligament reconstruction with acromioclavicular stabilization for acromioclavicular joint injuries. Am J Sports Med 2018;46:1070-1076.

42. Beitzel K, Obolpiwe E, Chowaniec D, et al. Biomechanical comparison of arthroscopic repairs for acromioclavicular joint instability: A suture button systems without biological augmentation. Am J Sports Med 2011;39:2218-2225.

43. Hislop P, Sakata K, Ackland DC, Gotmaker R, Evans MC. Acromioclavicular joint stabilization: A biomechanical study of bidirectional stability and strength. Orthop J Sports Med 2019;7:2325967119836751.

44. Le Hanneur M, Thoreson A, Delgrande D, et al. Biomechanical comparison of anatomic and extra-anatomic reconstruction techniques using local grafts for chronic instability of the acromioclavicular joint. Am J Sports Med 2018;46:1927-1935.

45. Li Q, Hsueh PL, Chen YF. Coracoclavicular ligament reconstruction: A systematic review and a biomechanical study of a triple button technique. Medicine (Baltimore) 2014;93:e193.

46. Lobao MH, Canham RB, Melvani RT, Parks BG, Murthi AM. Synthetic coracoclavicular ligament vs. coracoclavicular suspensory construct for treatment of acromioclavicular dislocation: A biomechanical study. J Shoulder Elbow Surg 2020;29:1440-1449.

47. Struhl S, Wolfson TS, Kummer F. Axial-plane biomechanical evaluation of 2 suspensory cortical button fixation constructs for acromioclavicular joint reconstruction. Orthop J Sports Med 2016;4:2325967116674668.

48. Naziri Q, Williams N, Hayes W, Kapadia BH, Chatterjee D, Urban WP. Acromioclavicular joint reconstruction using a tendon graft: A biomechanical study comparing a novel "sutured throughout" tendon graft to a standard tendon graft. SICOT J 2016;2:17.

49. Abat F, Sarasquete J, Natera LG, et al. Biomechanical analysis of acromioclavicular joint dislocation repair using coracoclavicular suspension devices in two different configurations. J Orthop Traumatol 2015;16:215-219.

50. Weiser L, Nüchtern JV, Sellenschloh K, et al. Acromioclavicular joint dislocations: Coracoclavicular reconstruction with and without additional direct acromioclavicular 
repair. Knee Surg Sports Traumatol Arthrosc 2017;25: 2025-2031.

51. Martetschläger F, Buchholz A, Sandmann G, et al. Acromioclavicular and coracoclavicular PDS augmentation for complete AC joint dislocation showed insufficient properties in a cadaver model. Knee Surg Sports Traumatol Arthrosc 2013;21:438-444.

52. Nüchtern JV, Sellenschloh K, Bishop N, et al. Biomechanical evaluation of 3 stabilization methods on acromioclavicular joint dislocations. Am J Sports Med 2013;41:1387-1394.

53. Clevenger T, Vance RE, Bachus KN, Burks RT, Tashjian RZ. Biomechanical comparison of acromioclavicular joint reconstructions using coracoclavicular tendon grafts with and without coracoacromial ligament transfer. Arthroscopy $2011 ; 27: 24-30$.

54. Staron J, Esquivel A, Pandhi N, Hanna J, Lemos S. Biomechanical evaluation of anatomical double-bundle coracoclavicular ligament reconstruction secured with knot fixation versus screw fixation. Orthopedics 2013;36: e1047-e1052.

55. Whiting P, Savović J, Higgins JPT, et al. ROBIS: A new tool to assess risk of bias in systematic reviews was developed. J Clin Epidemiol 2016;69:225-234.

56. Pill SG, Rush L, Arvesen J, et al. Systematic review of the treatment of acromioclavicular joint disruption comparing number of tunnels and graft type. J Shoulder Elbow Surg 2020;29:S92-S100.

57. Kowalsky MS, Kremenic IJ, Orishimo KF, McHugh MP, Nicholas SJ, Lee SJ. The effect of distal clavicle excision on in situ graft forces in coracoclavicular ligament reconstruction. Am J Sports Med 2010;38:2313-2319.

58. Klimkiewicz JJ, Williams GR, Sher JS, Karduna A, Des Jardins J, Iannotti JP. The acromioclavicular capsule as a restraint to posterior translation of the clavicle: A biomechanical analysis. J Shoulder Elbow Surg 1999;8: 119-124.

59. Renfree KJ, Wright TW. Anatomy and biomechanics of the acromioclavicular and sternoclavicular joints. Clin Sports Med 2003;22:219-237.

60. Ruiz Ibán MA, Moreno Romero MS, Diaz Heredia J, Ruiz Díaz R, Muriel A, López-Alcalde J. The prevalence of intraarticular associated lesions after acute acromioclavicular joint injuries is $20 \%$. A systematic review and meta-analysis [published online March 16, 2020]. Knee Surg Sports Traumatol Arthrosc. https://doi.org/10.1007/ s00167-020-05917-6.

61. Mistry H, Metcalfe A, Colquitt J, et al. Autograft or allograft for reconstruction of anterior cruciate ligament: a health economics perspective. Knee Surg Sports Traumatol Arthrosc 2019;27:1782-1790. 